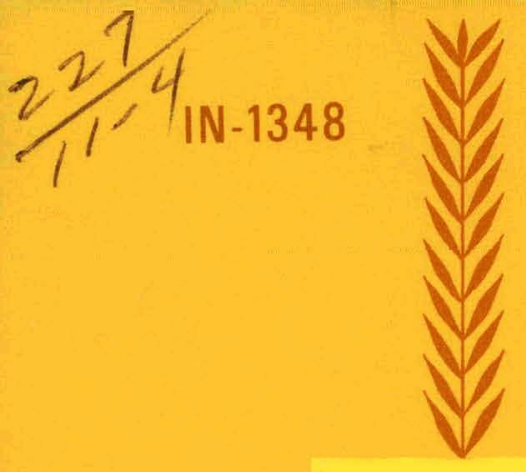

Dr-16/2

IN-1348

September 1970

MSTEP

\title{
EXPERIMENTAL INVESTIGATIONS OF REACTOR SYSTEM BLOWDOWN
}

G. F. Brockett H. D. Curet H. W. Heiselmann.

\section{IDAHO NUCLEAR CORPORATION NATIONAL REACTOR TESTING STATION \\ IDAHO FALLS, IDAHO}




\section{DISCLAIMER}

This report was prepared as an account of work sponsored by an agency of the United States Government. Neither the United States Government nor any agency Thereof, nor any of their employees, makes any warranty, express or implied, or assumes any legal liability or responsibility for the accuracy, completeness, or usefulness of any information, apparatus, product, or process disclosed, or represents that its use would not infringe privately owned rights. Reference herein to any specific commercial product, process, or service by trade name, trademark, manufacturer, or otherwise does not necessarily constitute or imply its endorsement, recommendation, or favoring by the United States Government or any agency thereof. The views and opinions of authors expressed herein do not necessarily state or reflect those of the United States Government or any agency thereof. 


\section{DISCLAIMER}

Portions of this document may be illegible in electronic image products. Images are produced from the best available original document. 
Printed in the United States of America Available from

Clearinghouse for Federal Scientific and Technical Information

National Bureau of Standards, U. S. Department of Commerce

Springfield, Virginia 22151

Price: Printed Copy $\$ 3.00$; Microfiche $\$ 0.65$

\section{LEGAL NOTICE}

This report was prepared as an account of Government sponsored work. Neither the United States, nor the Commission, nor any person acting on behalf of the Commission:

A. Makes any warranty or representation, express or implied, with respect to the accuracy, completeness, or usefulness of the information contained in this report, or that the use of any information, apparatus, method, or process disclused in this report may not infringe prixately owned rights; or

B. Assumes any liabilities with respect to the use of, or for damages resulting from the use of any information, apparatus, method, or process disclosed in this report.

As used in the above, "person acting on behalf of the Commission" includes any employee or contractor of the Commission, or employee of such contractor, to the extent that such employee or contractor of the Commission, or employee of such contractor prepares, disseminates, or provides access to, any information pursuant to his employment or contract with the Commission, or his employment with such contractor. 
IN-1348

Issued: September 1970

Reactor Technology

TID -4500

\title{
EXPERIMENTAL INVESTIGATIONS OF REACTOR SYSTEM BLOWDOWN
}

BY

G. F. Brockett

H. D. Curet

H. W. Heiselmann

\section{IDAHO NUCLEAR CORPORATION}

\author{
A Jointly Owned Subsidiary of \\ AEROJET GENERAL CORPORATION \\ ALLIED CHEMICAL CORPORATION \\ PHILLIPS PETAOLEUM COMPANY
}

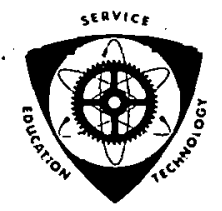

U. S. Atomic Energy Commission Scientific and Technical Report

Issued Under Contract AT(10-1)-1230

Idaho Operations Office 


\section{FOREWORD}

Thls report is based òn part 1 ot a paper, entitled "Reactor Systems Coolant Decompression Studies", presented by G. F. Brockett at a meeting on Decompression Effects of Water-Cooled Power Reactors in Frankfurt, Germany, June 9 through 13, 1969. Additional inform ation has been incorporated, primarily to make the report a complete summary of the 500,600 , and 700 Test Series of the Semiscale Blowdown and Emergency Core Cooling (ECC) Project. Information from early tests of the 800 series, contained in the original paper, has been retained in this report although a more complete summary of these tests can be found in other documents. 


\begin{abstract}
The purpose of the Semiscale Blowdown and Emergency Core Cooling (ECC) Project, discussed in this report, is to obtain experimental information describing the hydraulic, thermodynamic, and mechanical behavior of a simulated reactor system during loss of coolant for use in evaluating analytical models and codes for reactor safety assessment. The report presents the purpose of the experimental program as it relates to: (a) the need for experiments to test the analysis development, (b) the need for experimental data to answer specific questions unique to current 1000 megawatt pressurized water reactor(PWR) designs, and (c) the need for experimental data to answer specific questions arising in applying LOFT results to large power reactors. The experimental facilities, instrumentation, and measurements are described and the experimental results are presented and discussed. The subcooled behavior typifying that of the PWR systems is discussed prior to the two-phase behavior typifying the two-phase decompression phenomena of the PWR and boiling water reactor (BWR) systems. The results presented are described in relation to (a) the fundamental phenomena that are expected and prescribed by analysis, (b) the specific need for experimental evaluation of an analysis area, and (c) the empirical needs of the analysis development for large systems. Implications of certain of the results to large power reactors and the effects of scaling are commented on in selected cases.
\end{abstract}




\section{SUMMARY}

The ability to predict the major events affecting the reactor system response to a loss-of-coolant accident (LOCA) is of considerable importance in establishing the requirements for and predicting the performance of emergency core cooling systems. The reactor system coolant decompression, one of the controlling events of the LOCA, is receiving considerable attention In the Water Reactor Safety Program of the USAEC to assure that the predictive techniques describing the decompression, or blowdown process, can accurately account for thrust loads on the coolant envelope, pressure differential and drag loads on reactor internals, blowdown coolant availability for core cooling, core cooling resulting from blowdown, emergency core coolant influence on blowdown, and thermal-hydraulic loading of the containment over complete ranges of primary system break locations and sizes.

In the Semiscale Blowdown and Emergency Core Cooling (ECC) Project described in this report, experimental information has been obtained from decompression tests on small scale systems of varying degrees of complexity up to and including a complete primary loop and reactor vessel internal geometry. This information has enhanced the understanding of thrust, pressure differential, and thermal stress load generation. Also, knowledge of subcooled and two-phase decompression dependence on system geometric parameters and of methods of mitigating thrust and pressure differential loads has been obtained.

Among the conclusions, relevant to the safety assessment of large pressurized water reactors, which have thus far been drawn from this program, are the following:

(1) Break times 'for large breaks (greater than $30 \%$ of the pipe area over a wide range of distances from the break to the vessel area) in currently designed large power reactors must be in excess of 50 to $100 \mathrm{msec}$ before the subronled desompression process may be ignored an a potontinl anureo of damage and of altering the fluid state $(\rho, P, T)$ in the core prior to the two-phase portion of blowdown.

(2) For large rapid breaks relatively close to the reactor vessel the fluid undergoes a sonir relaxation process that results in high fluid velocity in the exit pipe. The high fluid velocity and the location of the break, whether in the inlet or outlet piping, bear significantly on the fluid state within the primary system at the beginning of the two-phase portion of blowdown. The effect of high velocity. for a hot-leg break is to increase the time hefore departure from nucleate boiling (DNB) is reached in the core. The increased time-to-DNB is desirable in that a great deal of the stored energy within the core is removed during this period. If the same break were to occur in a cold leg, the subcooled fluid velocity change necessary to support the decompression process would result in the potential to bring the core fluid velocity to nearly zero or in some cases to actually reverse the core flow existing prior to system rupture. Flow reversal in the core is undesirable 
because it may initiate early DNB and consequently demand early action of the emergency core cooling system while the blowdown process is still maintaining a high pressure.

(3) If the differential pressure loads observed in the semiscale system are properly scaled to a large reactor, their duration would be approximately ten times longer, or about 20 to 30 msec. For many of the reactor systems that have been designed to date, either small or large, the major members which support the core mass have natural periods of between 10 and $30 \mathrm{msec}$. The duration of the loads are thus seen to be comparable to the natural periods of the structures requiring then that the structures withstand these loads according to steady state design criteria as opposed to impulse'criteria for smaller systems.

(4) The general system pressure history of the decompression is a poor index of the fluid behavior taking place within the fluid envelope. To provide comprehensive evaluation of predictive analyses, particularly those that incorporate core heat transfer, future experiments must provide histories of local conditions of fluid state $(\rho, P, T)$ and fluid velocity.

(5) Considerably more experimental work is required in which representative reactor internal geometries are employed and across which a core differential temperature is initially established. This work is needed to ascertain for hot-leg breaks the core fluid behavior during the period in which the fluid quality and velocity of sound are low causing the recovery of established flow within the core reglon to be delayed inordinately, thereby contributing to an early and rapid core heatup. 
FOREWORD $\ldots \ldots \ldots \ldots \ldots \ldots \ldots \ldots \ldots \ldots \ldots \ldots \ldots \ldots \ldots \ldots \ldots$ ii

ABSTRACT $\ldots \ldots \ldots \ldots \ldots \ldots \ldots \ldots \ldots \ldots \ldots \ldots \ldots \ldots \ldots \ldots \ldots$ iii

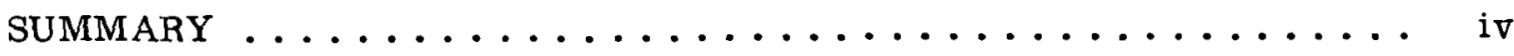

I. INTRODUCTION .................... 1

II. EXPE RIMENTAL SYSTEMS DESCRIPTION .......... 5

1. INITIAL TEST CONDITIONS $\ldots \ldots \ldots \ldots \ldots \ldots \ldots \ldots$

3. TEOIINIQUES FOR PRODUCING RUPTURE ......... 1 b

3. EXPE RIMENTAL INFORMATION OBTAINED $\ldots \ldots \ldots \ldots \ldots$

4. DATA ACQUISITION EQUIPMENT . . . . . . . . . . 19

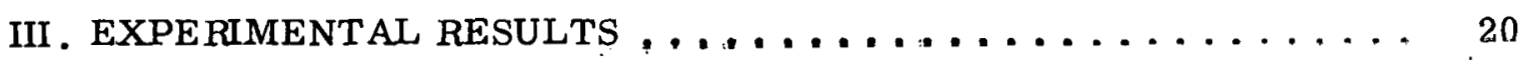

1. RESULTS FOR SUBCOOLED DECOMPRESSION BEHAVIOR . . . 20

1.1 Decompression of Simple Fluid Behavior -- Vessel with Connecting Pipe but Void of Internals ............. 20

1.2 Decompression of Vessel with Connecting Pipe and

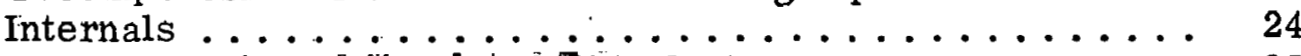

1.3 Decompression of Simulated PWR System ........... 25

2. RESULTS FOR TWO-PHASE DECOMPRESSION BEIAVIOR . . . . 31

2.1. General Two-Phase Decompression Behavior........... 31

2.2 Factors Affecting Coolant Decompression Within the

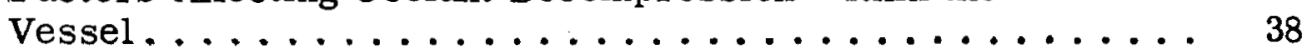

2.3 Structural Response to Coolant Decompression . . . . . . . . . 42

IV. DISCUSSION OF THE RELEVANCE OF THE EXPERIMENTAL

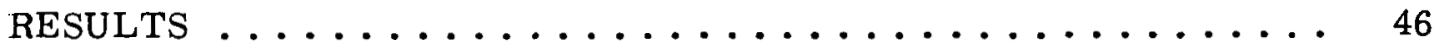

1. SIGNI FICANCE OF BRE AK RATE ... . . . . . . . . . 46

2. SIGNIFICANCE OF SUBCOOLED FLUID VELOCITY ON CORE

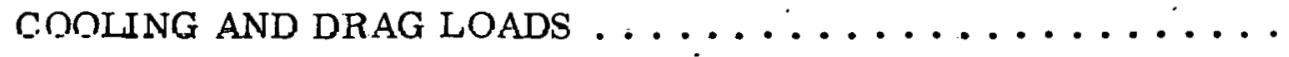

3. SIGNI FIC ANCE OF SUBCOOLED LOADS DURATION TO DAMAGE

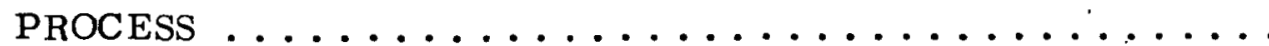

4. SIGNIFICANCE OF TWO-PHASE DECOMPRESSION

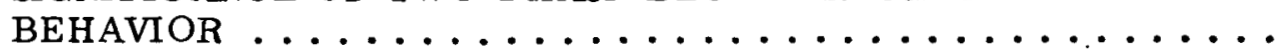

V. REFERENCES ........................... 49 


\section{FIGURES}

1. Test series 500 vessel -- bottom break -- Configuration A ..... 6

2. Test series 500 vessel -- top break -- Configuration B . . . . . . . 7

3. Test series 600 vessel -- LOFT core model -- Configuration C . . . 8

4. Test series 600 vessel -- inertance core (Test 609) -- Configuration

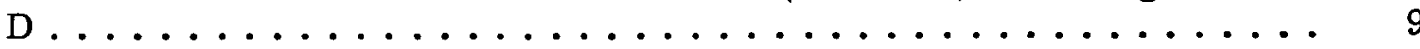

5. Test series 700 vessel -- void of internals (Tests 704,706 , and 710 ) --

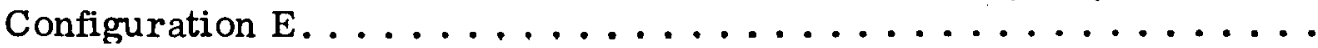

6. Test series 700 vessel -- PWR annulus representation (Test 711) --

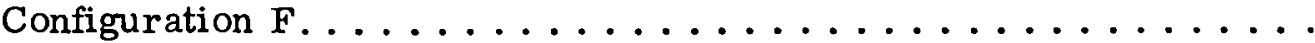

7. Test series 700 vessel -- resistance core (Test 714)-- Configuration

8. Test series 800 - top break -- Configuration H ........... 13

9. Test series 800 system -- Configuration I . . . . . . . . . . . 14

10. Rupture device ............................ 16

11. Plenum and pipe pressurization and nozzle fluid velocity for full nozzle area break - exit acoustic impedance much less than nozzle acoustic

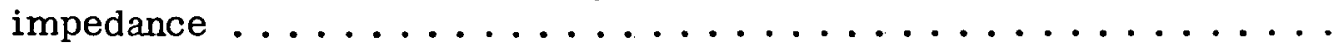

12. Plenum and pipe pressurization and nozzle fluid velocity for $10 \%$ nozzle area break -- exit acoustic impedance equivalent to nozzle acoustic

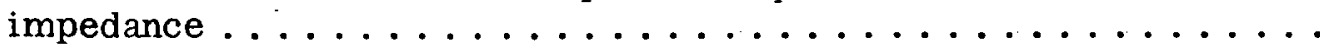

13. Plenum and pipe pressurization and nozzle fluid velocity for $6.25 \%$ nozzle area break -- exit acoustic impedance much greater than

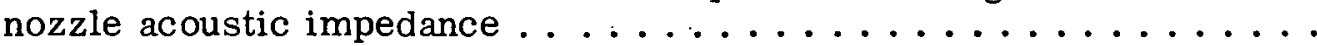

14. Differential pressure for simulated LOFT core -- core area $73 \%$ of plenum area -- core entrance and exit restriction $17 \%$ of plenum

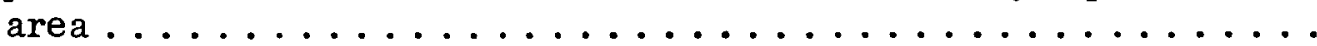

15. Inertance core differential pressure -- core area $6 \%$ of plenum

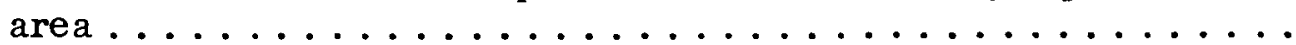

16. Simulated PWR inlet annulus and plenum depressurization . . . . . . 27

17. Pressure difference across core support barrel -- barrel with and without pressure relief holes - P8 minus Pl ............... 28

18. Pressure difference across reactor core -- barrel with and without pressure relief holes - P8 minus P7 . . . . . . . . . . 
19. Subcooled decompression histories at each end of the semiscale heat exchanger and the resulting pressure differential history ........

20. Methods for evaluating fluid temperature and pressure in relation to equilibrium conditions prescribed by standard steam tables and also an index of measurement system performance ..............

21. Two-phase vessel pressure and temperature history .........

22. Comparison of vessel pressure histories for top and bottom blowdown

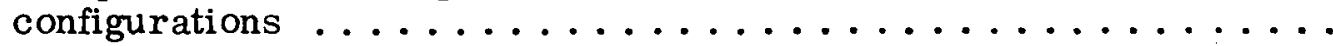

23. Stagnation pressure one pipe diameter from nozzle exit $500 \mathrm{msec}$ after $t_{0}$ for top and bottom blowdown tests $\ldots \ldots \ldots \ldots \ldots$

24. Total decompression history comparison for large and small

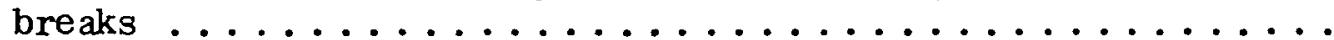

25. Fluid decompression in a vessel with accentuated hydraulic

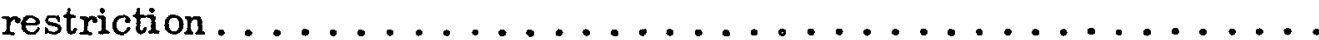

26. Decompression pressure histories for vessel with and without a

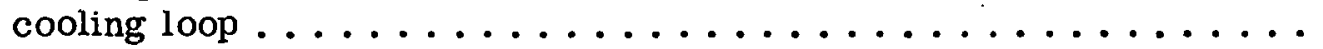

27. Pressure behavior in exit pipe for normal and abnormal conditions of choking at the pipe entrance ..................

28. Residual water in vessel following decompression for various vessel geometries and break conditions ................

29. Vessel thrust developed in two-phase decompression compared to

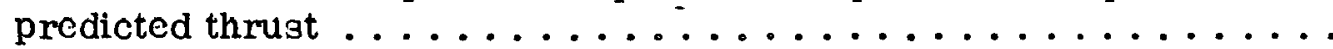

30. Thermal stress history developed on coolant piping during decompression for several break sizes................

\section{TABLES}

I. Semiscale Blowdown and Emergency Core Cooling (ECC) Project....

II. Detector Descriptions for Typical Measurements used in Semiscale Blowdown and Emergency Core Cooling (ECC) Project .......... 


\section{EXPERIMENTAL INVESTIGATIONS OF REACTOR SYSTEM BLOWDOWN}

\section{INTRODUCTION}

The reactor system coolant decompression, resulting from the unlikely event of a loss-of-coolant accident (LOCA) in a water-cooled and -moderated nuclear reactor becomes a controlling event in the sequence of events that determine whether a nuclear core will be cooled adequately by emergency safety systems or will undergo metal-water reaction and possibly melt down.

The capability of predicting the coolant decompression process, or blowdown, and the simultaneous or subsequent events of (a) core power decline, (b) loss of core cooling, and (c) structural response of reactor internals and coolant envelope to blowdown forces, must be developed to a high degree if assurance of emergency safety system design adequacy and performance is to be established.

The analysis development and verification for the required degree of predictability is difficult for a number of reasons:

(1) The decompression event is a transient process in which changes in typical phenomena are occurring differently in different parts of the system, thus requiring a "distributed system" as opposed to a "lumped" analysis approach

(2) The large size and cost of nuclear power plants prohibit testing of accident response at full scale, thus necessitating incorporating within the analysis the capability of accounting for scaling and of accommodating those factors that cannot be scaled

(3) The interactions of such processes as structural displacements with hydraulic loading, core heat removal with coolant decompression, and liquid-steam phase separation with emergency coolant injection require that many of the otherwise separable analyses be coupled with consequent increase in computer operating cost and numerical instabilities

(4) The experimental data available for development of correlations for determining two-phase fluid effects and heat transfer have been derived from steady state tests and have uncertainty in application to the transient situation

(5) The core region and surrounding fluid passages must be represented in more than one dimension, whereas at present most analyses have been performed for one dimension only.

To provide experimental information to assist in analysis evaluation, investigations have been conducted for the past several years at the National Reactor Testing Station (NRTS), first by Phillips Petroleum Company and presently by Idaho Nuclear Corporation. These experimental investigations, 
identified as the Semiscale Blowdown and Emergency Core Cooling (ECC) Project[1], are part of the Water Reactor Safety Program sponsored by the United States Atomic Energy Commission.

The purpose of the Semiscale Blowdown and Emergency Core Cooling (ECC) Project is to obtain experimental information describing the hydraulic, thermodynamic, and mechanical behavior of a simulated reactor system during loss of coolant for use in evaluating analytical models and codes for reactor safety assessment[2].

At present, insufficient data exist to provide the necessary information on decompression (blowdown) behavior in an actual reactor system geometry. The blowdown tests that have been performed were conducted in simple pressure vessels with no core heating, connecting piping, or other primary system components such as pumps, valves, and heat exchangers. An urgent need exists for blowdown test data with simulated core heat and ECC injection in a system having a geometry representative of that of power reactors. These data are considered essential for evaluating the prediction analyses currently being used for safety assessment. The experimental results are also needed to provide an evaluation of analyses for the Loss-of-Fluid Test (LOFT) Program[3] so that the LOFT test conditions selected by means of the analyses will provide a comprehensive assessment of the ECC concept.

Emphasis in the Semiscale Blowdown and Emergency Core Cooling (ECC) Project is on system aspects which influence the blowdown behavior. The detailed hydrodynamics and other physical processes are being studied by many investigators and are incorporated within the predictive analysis to the extent possible. With this approach the experiments are able to test as well as guide the analysis in the degree of spatial and dynamic process representation appropriate to predicting. the important features of the coolant decompression resulting from a loss-of-coolant accident.

The primary objectives of the Semiscale Blowdown and Emergency Core Cooling (ECC) Project are to determine:

(1) Availability of primary coolant fluid for core cooling during blowdown following a break in a simulated primary system

(2) Demand requirements for ECC delivery to the core and the importance of various parameters affecting that demand

(3) Efficiency of ECC delivery from the point of primary system injection to the core

(4) Forces generated during blowdown and the mechanical response to those forces by system components and simulated reactor internals.

Secondary objectives are to obtain related experimental information for use in evaluating the analytical capability to predict the course of a LOCA. This information includes: 
(1) Thermal shock and other forces resulting from ECC injection

(2) Performance margins of current designs of ECC systems

(3) Mixing behavior of primary and ECC fluids.

The Semiscale Blowdown and Emergency Core Cooling (ECC) Project consists of six series of tests in which each succeeding series employs equipment representing an increased degree of simulation of a commercial PWR system. The Project is summarized in Table I. The 500,600, and 700 series of tests, completed in June 1968[4-11], investigated coolant depressurization in a simulated reactor vessel with and without unheated reactor internals to model the hydraulic aspects of large PWR internals.

TABLE I

SEMISCALE BLOWDOWN AND EMERGENCY CORE COOLING (ECC) PROJECT

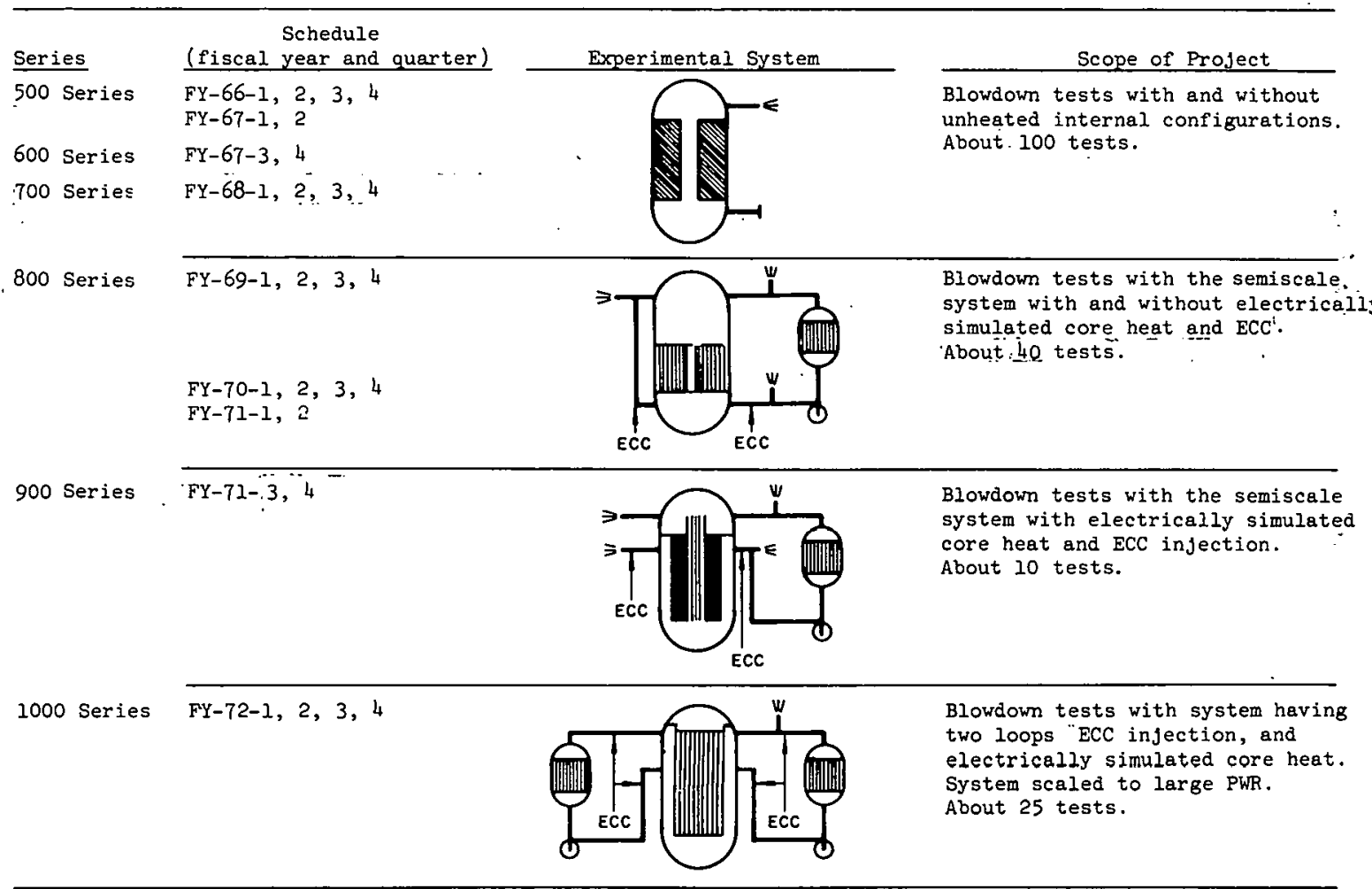

The 800 test series currently in progress will investigate the mechanical response of a single-loop primary system to coolant depressurization and the effect the coolant in the primary system has on the system depressurization. The series is made up of three types of tests. The first type[12] investigated the effect of adding a primary loop to an empty reactor vessel. The second type will study the effect of core heat. The third type, which will include rupture of a simulated second loop, will provide scoping information on injection of emergency core coolant. Reactor core heat for this test series will be simulated by use of an array of electrically heated pins having a 0.44 -inch diameter and a 9-inch he ated length. 
Test Series 900 will utilize the experimental loop and vessel of the 800 test series, with a longer core, to investigate the effect of a longer core and internal downcomer on the delivery capabilities of the emergency core cooling system in a blowdown environment. The system used for the 1000 test series will have two coolant loops to provide information on the coolant decompression and on the influence of introducing emergency coolant into a multiple loop model of a large PWR reactor system. 


\section{EXPERIMENTAL SYSTEMS DESCRIPTION}

The data presented in this report were derived from the $500,600,700$, and 800 test series configurations detailed in Figures 1 through 9 .

\section{INITI AL TEST CONDITIONS}

The initial fluid conditions for the various test series generally simulated typical liquid-full PWR fluid conditions. The initial fluid conditions for Test Series 500, 600, and 700 .were provided by a small capacity primary system which included a makeup system, pressurizer, and in-line heaters. This system was isolated from the vessel before blowdown initiation to maintain the fluid in the experimental vessel in a stagnant condition before blowdown and to permit only this fluid to be subjected to blowdown conditions.

The initial conditions for Test Series 800 were provided by an operating primary system, shown in Figure 9 , about one-tenth the linear size of a primary system for a $1000 \mathrm{MW}(\mathrm{e})$ PWR. The fluid temperature conditions for these tests were obtained through use of auxiliary heaters. The fluid in the complete primary system was allowed to decompress during the 800 test series. 


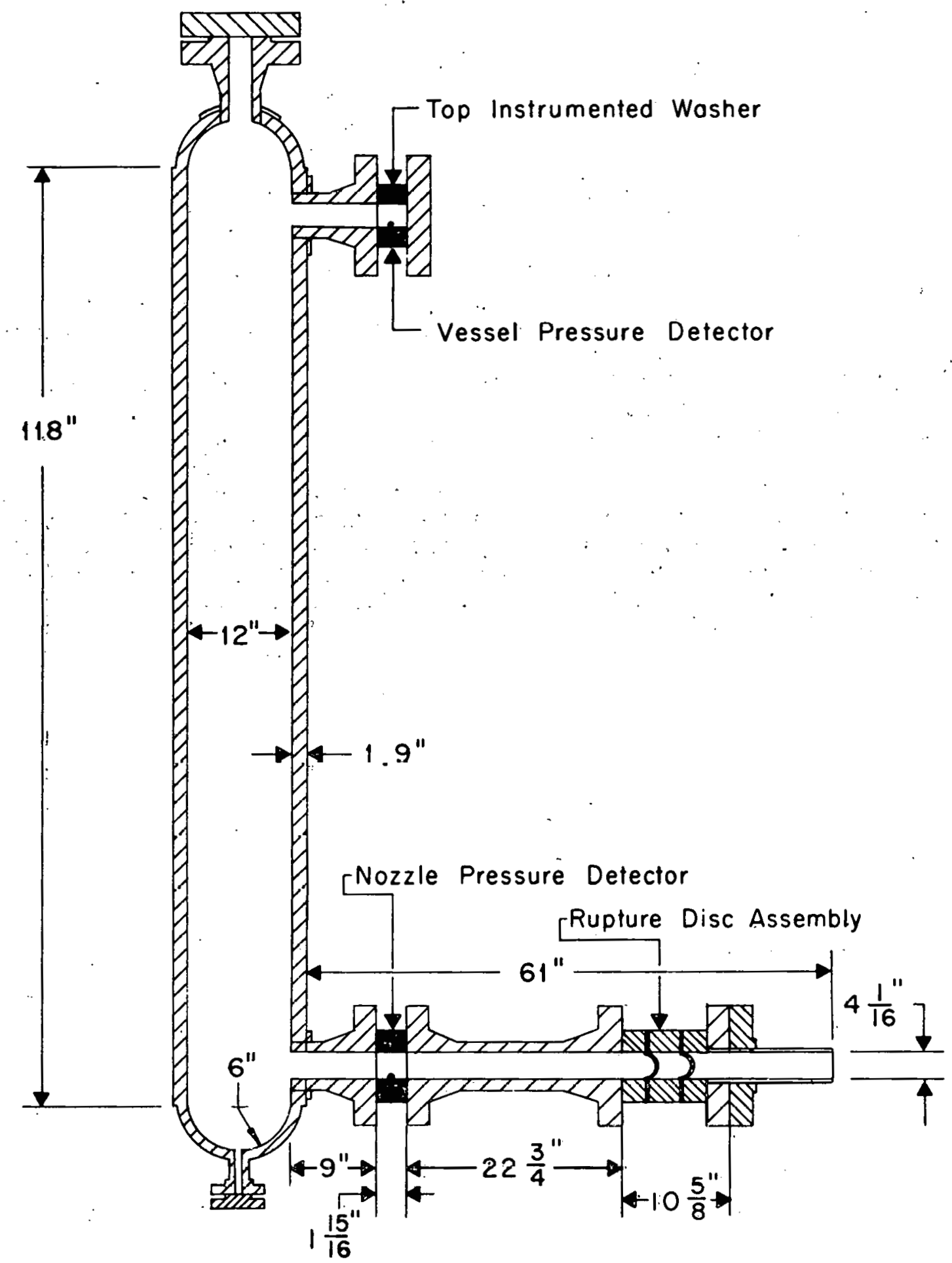

AOS-2556

FIG. I TEST SERIES 500 VESSEL - BOTTOM BREAK - CONFIGURATION A.

6. 


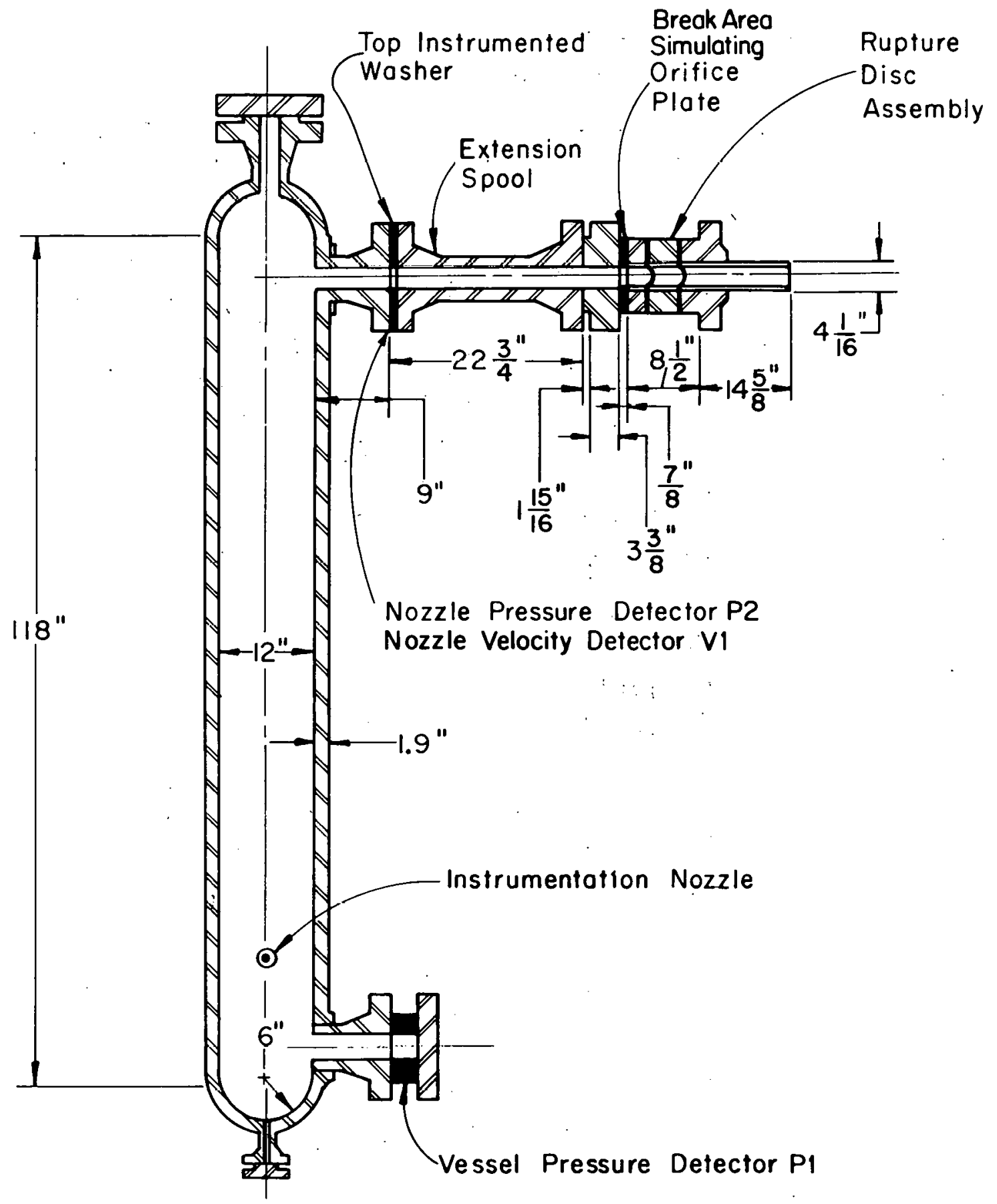

AOS-2557

FIG. 2 TEST SERIES 500 VESSEL -- TOP BREAK -- CONFIGURATION $B$.

7 


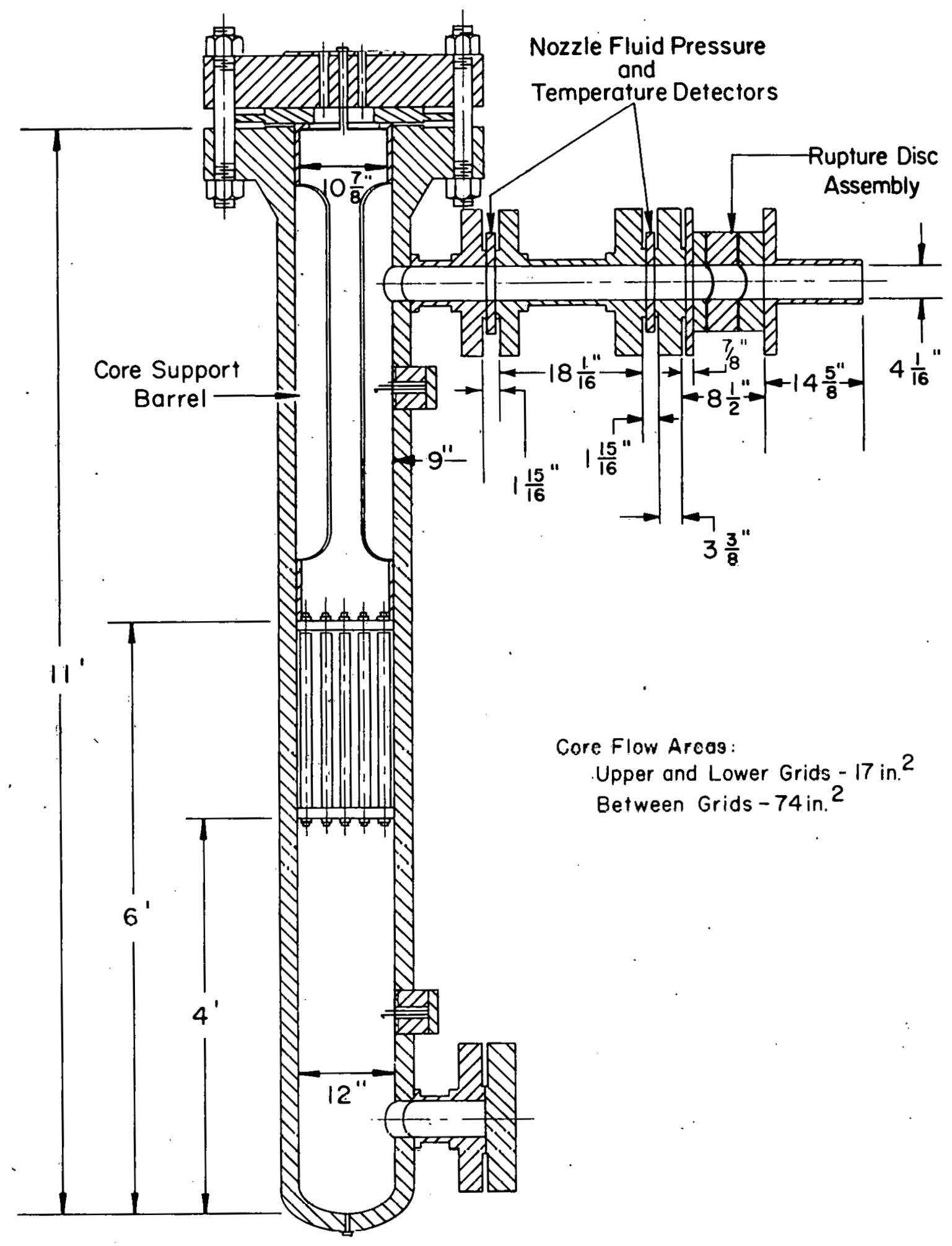

AOS-2553

FIG. 3 TEST SERIES 600 VESSEL -- LOFT CORE MODEL -- CONFIGURATION $C$. 


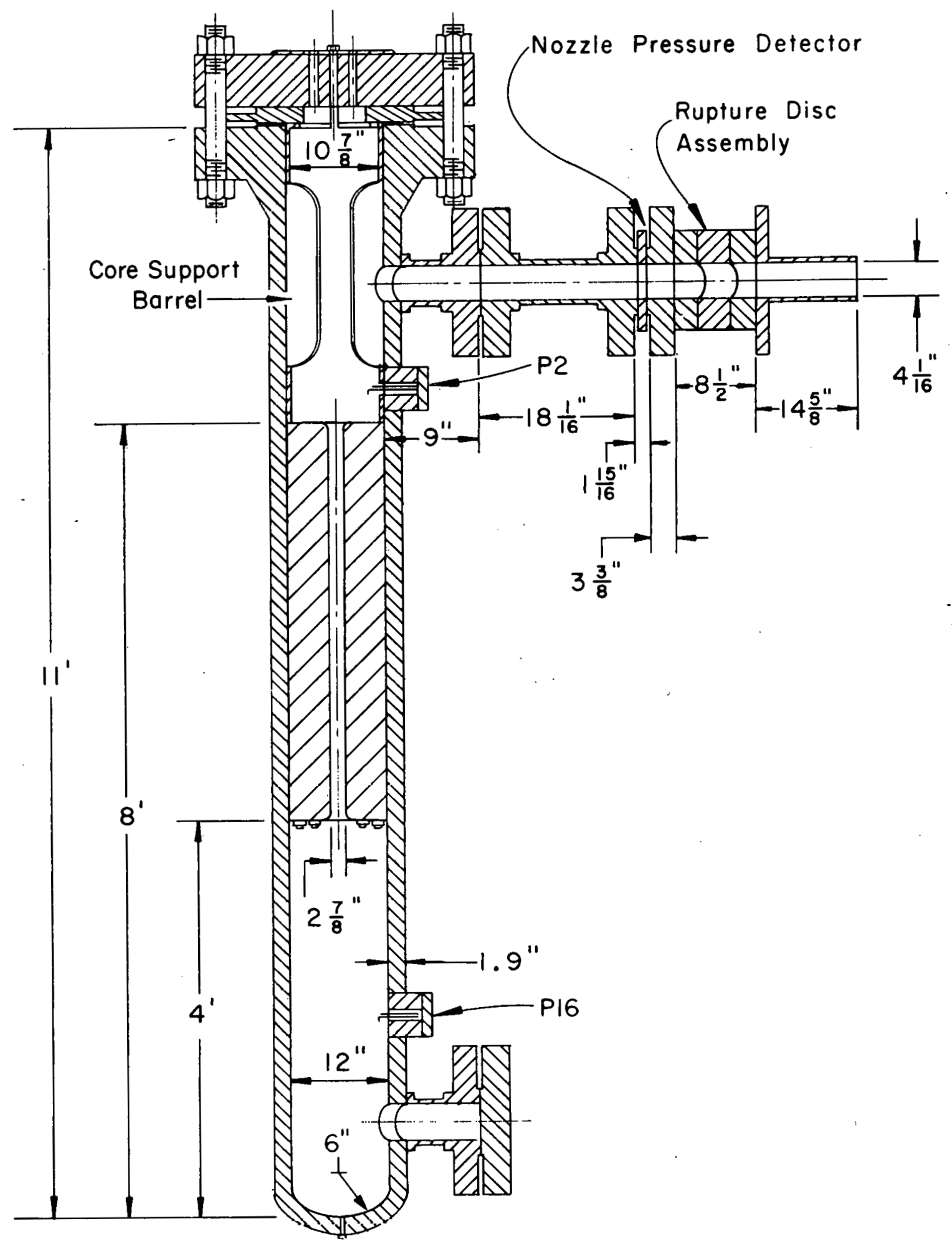

AOS -2559

FIG. 4 TEST SERIES 600 VESSEL -- INERTANCE CORE (TEST 609) -- CONFIGURATION D. 


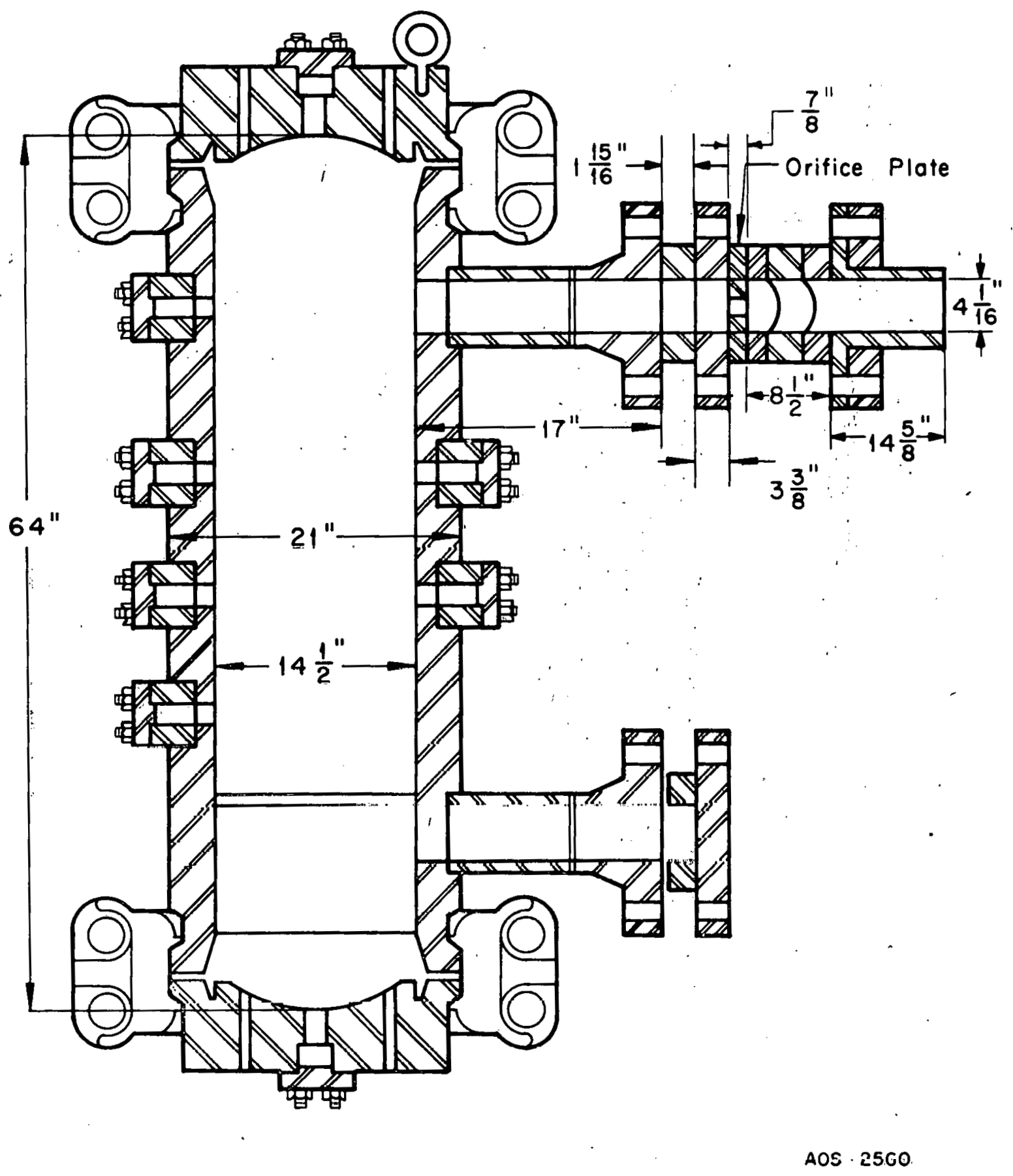

FIG. 5 TEST SERIES 700 VESSEL - VOID OF INTERNALS (TESTS 704, 706, AND 710) -CONFIGURATION E. 


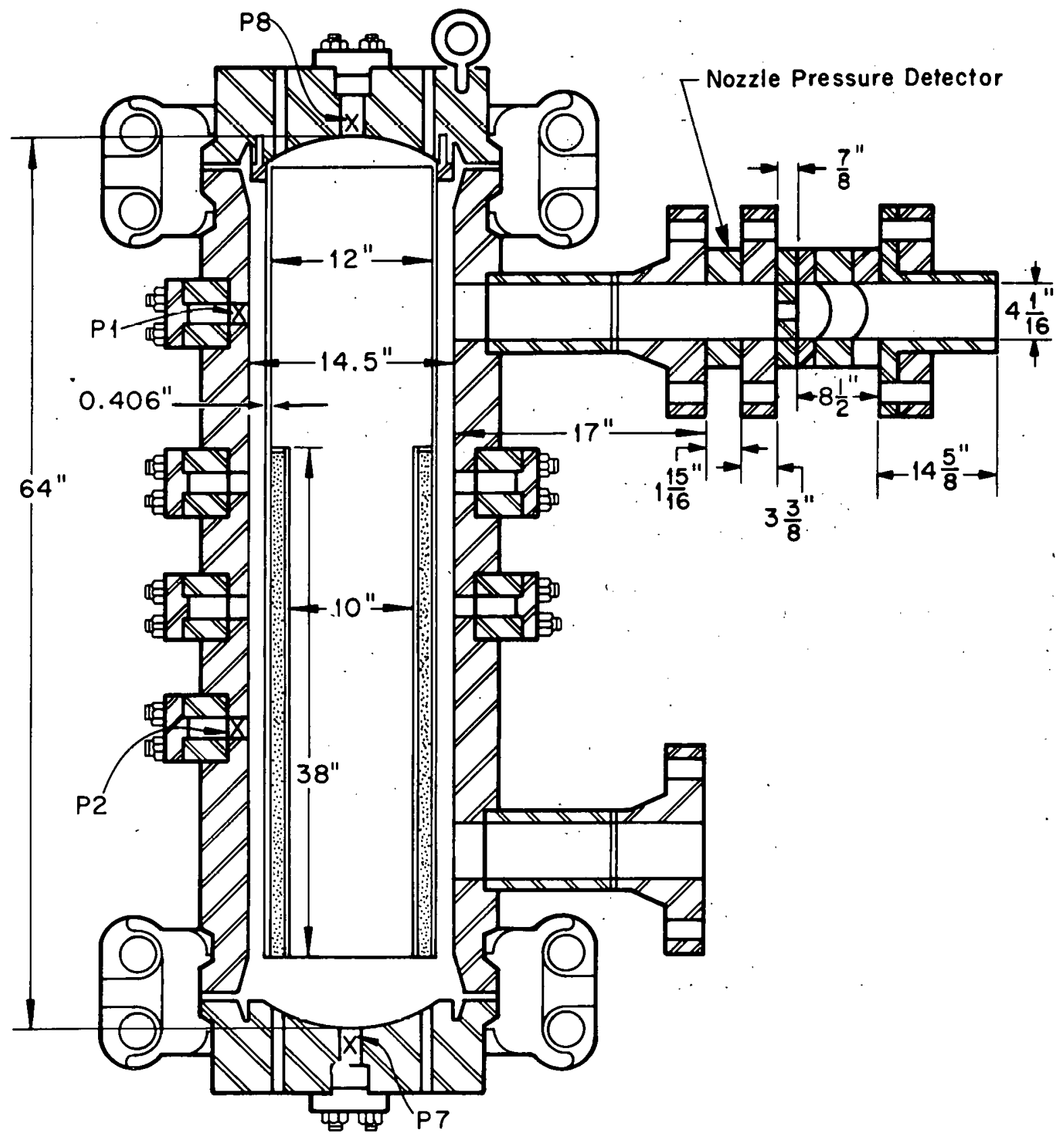

AOS-2561

FIG. 6 TEST SERIES 700 VESSEL - PWR ANNULUS REPRESENTATION (TEST 711) -CONFIGURATION F. 


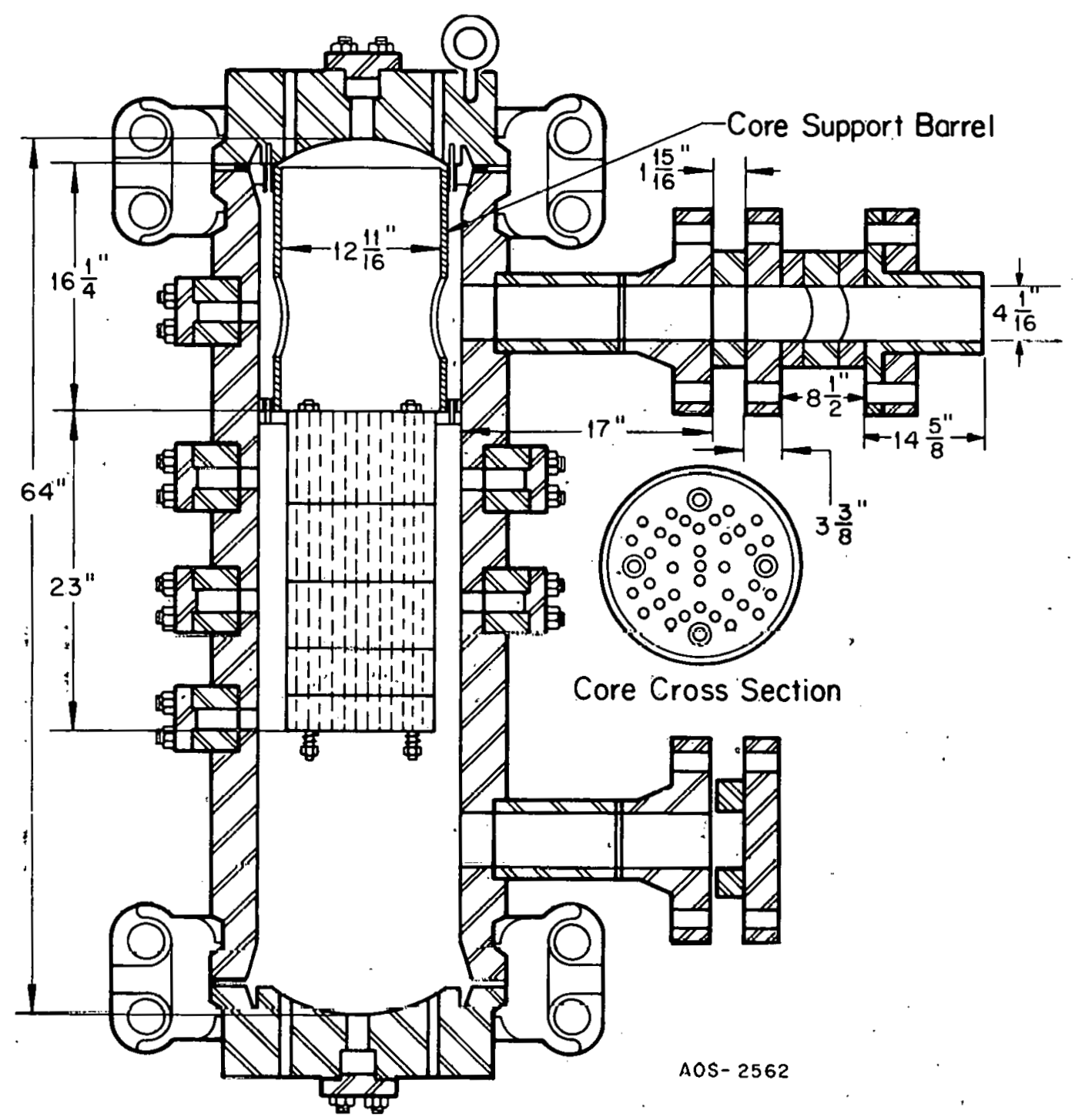

FIG. 7 TEST SERIES 700 VESSEL - RESISTANCE CORE (TEST 714) T- CONFIGURÁtion G. 


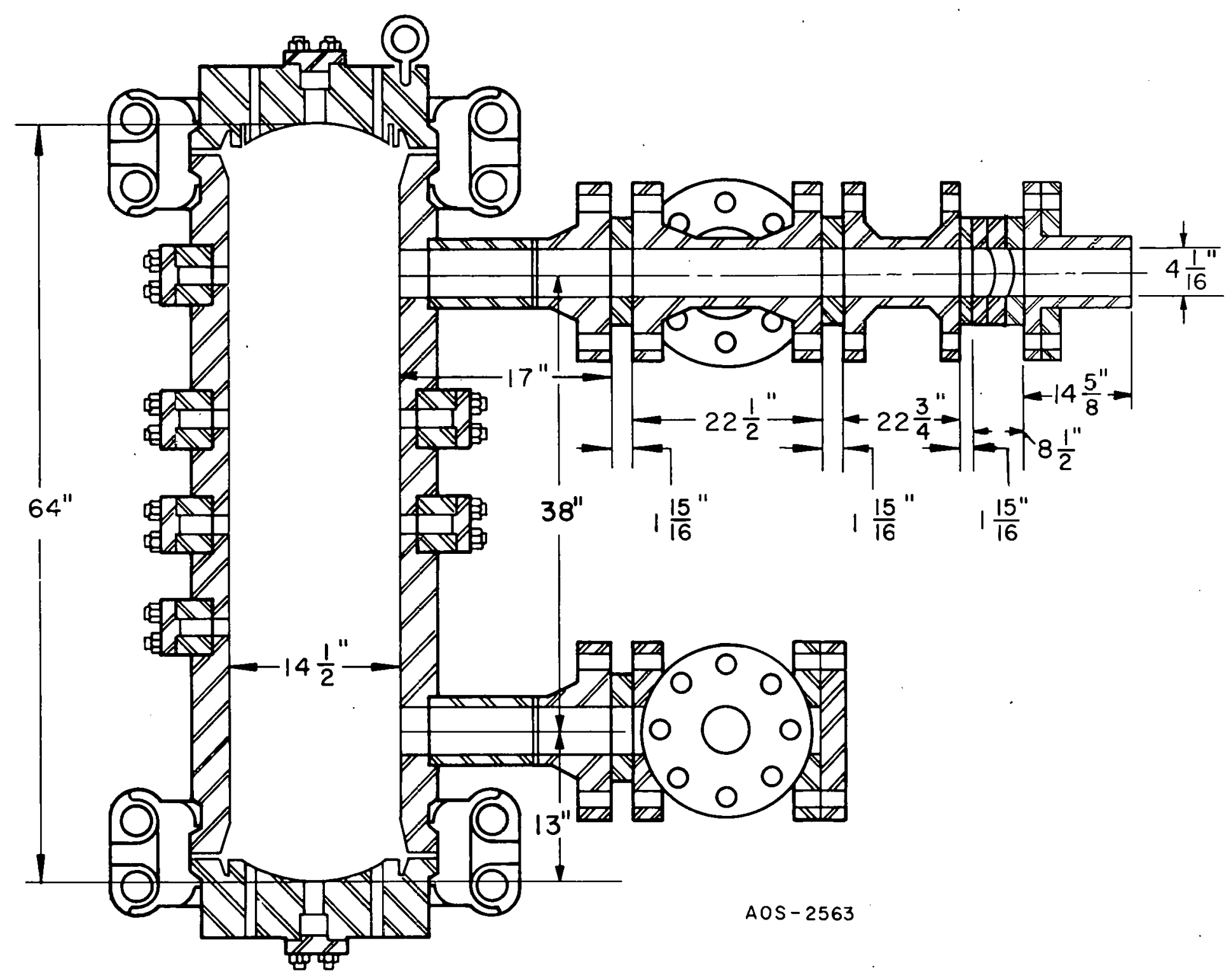

FIG. 8 TEST SERIES 800 - - TOP BREAK -- CONFIGURATION H. 


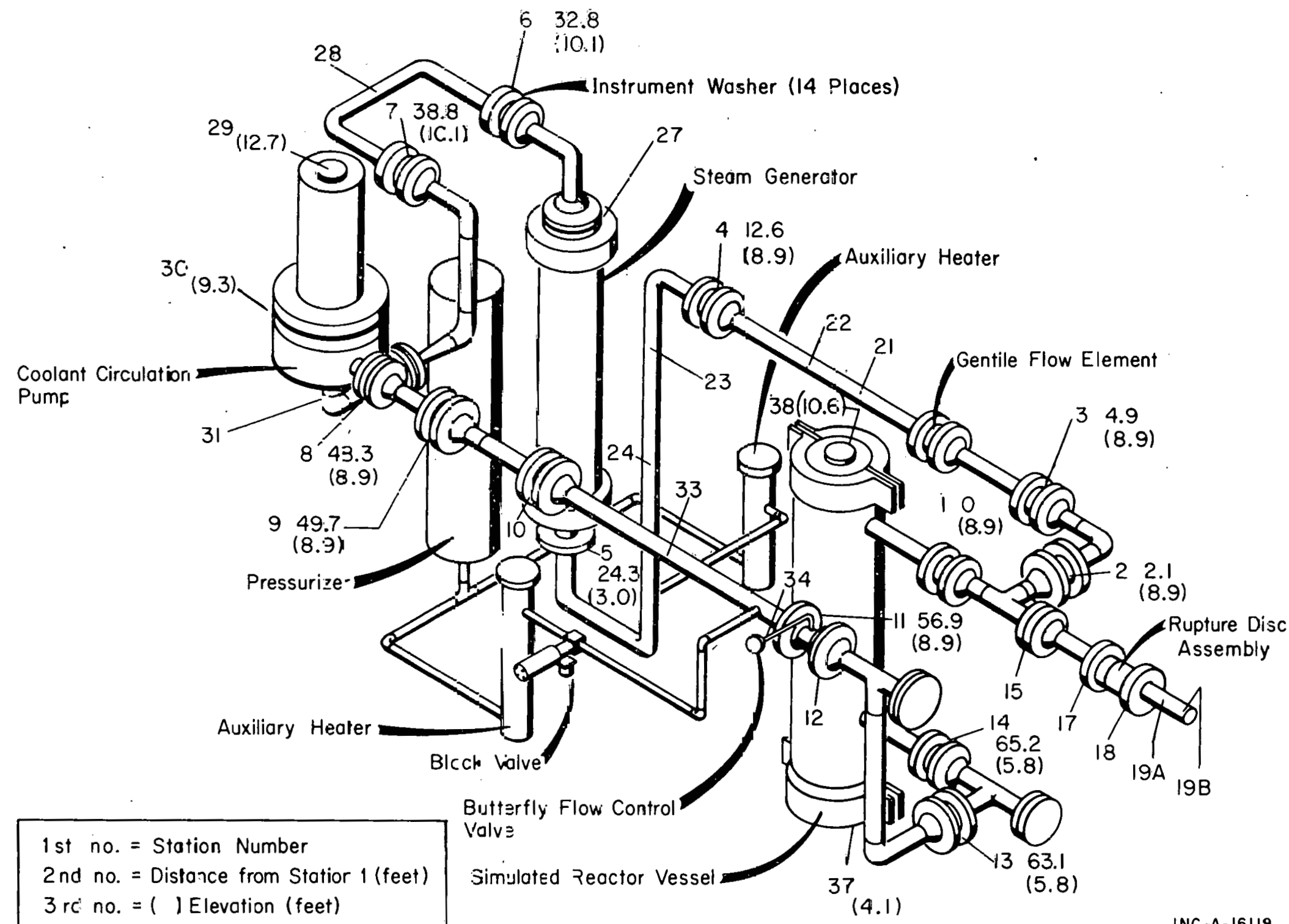

FIG. 9 TEST SERIES adO SYSTEM -- CONFIGURATION 1. 


\section{TECHNIQUES FOR PRODUCING RUPTURE}

The depressurization was initiated by the rupture device shown in Figure 10. This device consists of a series of pipe spools and rupture disc flanges that $c$ an be bolted to either the top or bottom vessel nozzles. Ruptures can be initiated hy either of two techniques. For one technique, the rupture discs are overpressurized with nitrogen released into the volume between the rupture discs from pressure accumulators. The second rupture technique involves depressurizing, or underpressurizing, the volume between the rupture discs. The area of the rupture is determined by the orifice plate employed.

The rupture times obtained with the metal discs range from approximately 0.4 to $1.0 \mathrm{msec}$. These times are considered to be less than the actual time required to rupture a pipe that is at PWR fluid conditions. Consequently, an instantaneous subcooled fluid-decompression behavior is prevalent in the semiscale tests. This behavior may be somewhat more severe than would actually prevail during loss of coolant from a reactor. 


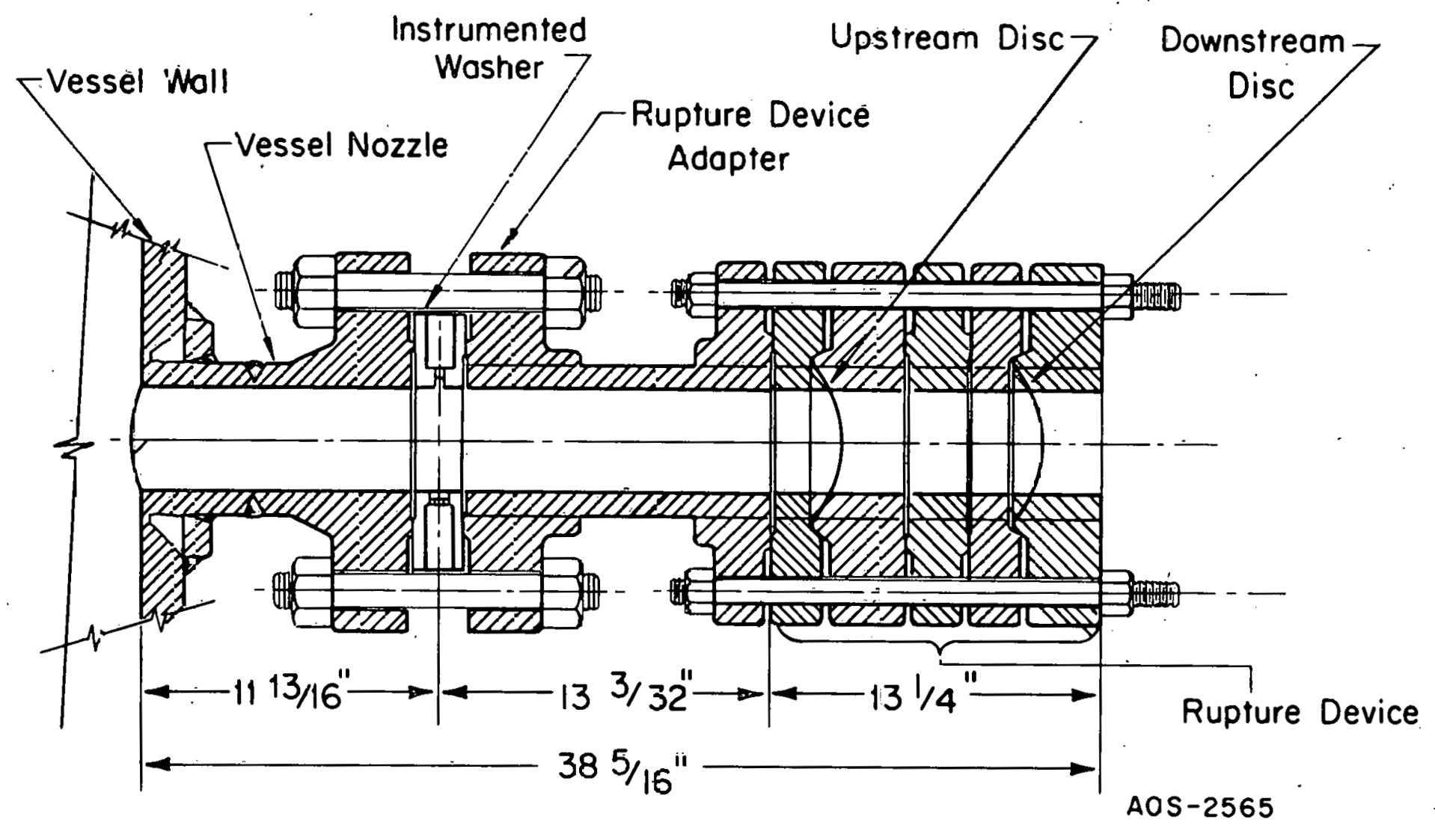

Fie, 10 Rupture DeVICE. 


\section{EXPERIMENTAL INFORMATION OBTAINED}

The blowdown experiments provide information relating to the following general areas: (a) depressurization mechanisms in the coolant loop and vessel, (b) transient pressure gradients and hydraulic loads imposed on the loop components and the core, (c) flow within the system during blowdown, (d) mass discharge rate, (e) water remaining in the system after pressure equilibrium, and (f) heat transfer mechanisms that control the core thermal response and fluid envelope transient thermal stress.

The measurements required to provide pertinent information in these areas fall into the categories of fluid property measurements, mechanical response measurements, and vessel wall temperature measurements. Typical devices used to make these measurements are listed in 'Table II.

The fluid property measurements include fluid temperature and pressure, mass velocity, density, and water level measurements.

Mechanical measurements include displacement, strain, thrust, and acceleration measurements on the primary piping and components, vessel, and simulated reactor internals. 


\section{TABLE II}

DETECTOR DESCRIPTIONS FOR TYPICAL MEASUREMBITTS USED IN SEMISCALE BLONLOWN AND EMLRTENCY CORE COOLING (ECC) PROJECT

\begin{tabular}{|c|c|c|c|c|}
\hline Measurement & Manufa=turer & Type & Range & Response \\
\hline Fluid pressure & Norwcod & Strain gage & 0 to 3000 psig & $\mathrm{dc}-20 \mathrm{kHz}$ \\
\hline Fluid pressare & Kistler & Crystal & 0 to $5000 \mathrm{psig}$ & $5 \mathrm{~Hz}-1000 \mathrm{kHz}$ \\
\hline Fluid pressure & Dymisco & Strain gage & 0 to $3000 \mathrm{psig}$ & $\mathrm{dc}-20 \mathrm{kHz}$ \\
\hline Fluid temperature & Nanmac & $\begin{array}{l}\text { Abrade } \bar{c} \text { (Chromel- } \\
\text { Alumel) }\end{array}$ & $2500^{\circ} \mathrm{F}$ & $1 \mathrm{kHz}$ \\
\hline Well temperature & $\begin{array}{l}\text { Phillips } \\
\text { Petroleun Company }\end{array}$ & $\begin{array}{l}\text { Bare (Chromel- } \\
\text { Alumel) }\end{array}$ & $2500^{\circ} \mathrm{F}$ & $1 \mathrm{kHz}$ \\
\hline Strain & $\begin{array}{l}\text { Micro } \\
\text { Measurements }\end{array}$ & $\begin{array}{l}\text { Strain gage } \\
\text { (epoxy-backed } \\
\text { fo:l gages) }\end{array}$ & 0 to $2000 \mu \mathrm{in} . / \mathrm{in}$. & $\mathrm{dc}-1 \mathrm{kHz}$ \\
\hline Water level & $\begin{array}{l}\text { Phillips } \\
\text { Petroleun Company }\end{array}$ & Manoneter & 0 to 30 in.. & --- \\
\hline
\end{tabular}




\section{DATA ACQUISTTION EQUIPMENT}

The data acquisition equipment used in the coolant decompression testing incorporates 78 channels of fast-response low-drift, wide dynamic range, signal conditioning and magnetic tape recording equipment. The signal conditioning equipment is calibrated and monitored semiautomatically and is maintained with an overall noise threshold of $10 \mu \mathrm{V}$ at the detector input, thereby providing a dynamic range of at least $2-1 / 2$ decades for most detectors. The magnetic tape recorders are operated in the frequency modulation mode at $60 \mathrm{in} . / \mathrm{sec}$ producing a dc to $20 \mathrm{kHz}$ frequency response.

Results of tests performed on the overall instrumentation system have shown the accuracy and linearity of the complete instrumentation system, excluding the measurement detectors, and data processing system to be to within $\star 1 \%$ of full scale up to $3 \mathrm{kHz}$. 


\section{EXPERIMENTAL RESULTS}

The presentation of the experimental results is in the form of typical plots that define and describe the time behavior of events and processes taking place during the coolant decompression of a reactor system which, in the simplest form, is represented by a vessel and section of connecting pipe. Results from decompression of more complicated geometries, including a vessel with various simulated reactor internals and a vessel with a complete primary system loop, are also presented and discussed. The figures are intended to be as selfcontained as possible; however, a configuration of the fluid envelope is included on the figure to provide an index to the experimental systems (Figures 1 through 9).

The experimental data are presented and discussed in terms of the two separate processes; the subcooled decompression process and the two-phase decompression process. An interpretative discussion on the implication of the behavior portrayed in these two processes to the safety issues associated with large power reactor systems is given in Section IV.

\section{RESULTS FOR SUBCOOLED DECOMPRESSION BEHAVIOR}

The discussion of subcooled blowdown is addressed to the sonic-controlled system depressurization and attendant fluid flow behavior that cause hydraulic loads and affect the core coolant flow in the early part of blowdown.

\subsection{Decompression of Simple Fluid Envelope -- Vessel with Connecting Pipe but Void of Internals}

The first studies to be discussed are the subcooled experimental studies for a simulated reactor vessel with connecting piping but void of internals (Figures 1 and 2). When this geometry is considered, the fundamental form of the decompression process $c$ an be related to the Helmholtz phenomena[13]. For this particular fluid envelope geometry, excited in steady state, the Helmholtz phenomena is evidenced as a characteristic oscillating frequency controlled by the cyclic exchange of energy between the inertance of the fluid in the exit pipe and the compliance of the fluid in the vessel. For this system the sudden release of the stored energy within the system, as controlled by the sonic processes in the exit pipe, represents the first quarter cycle of the natural Helmholtz frequency for the particular geometry as shown by the BAM code[14].

The details of the syslem relaxation phenomena are as follows: If the exit nozzle is ruptured to a $100 \%$ pipe area, then for all practical purposes, each end of the nozzle appears to have a low acoustic impedance relative to the characteristic acoustic impedance of the fluid in the pipe. According to theory, any pressure disturbance reaching the discontinuity of an area change must transmit and reflect appropriate fractions of the energy. The magnitude of the fractional split is determined by the pipe-to-plenum impedance ratio at the discontinuity. The polarity of the reflected fraction is determined by whether the disturbance is propagating into an expansion or into a contraction at the discontinuity. For the case of the simple vessel subjected to a $100 \%$ 
outlet rupture, the decompression disturbance in the pipe is reflected as a recompression at the junction of the pipe with the plenum. The process is shown in Figure 11 in which the pipe pressure, P2, appears as a series of decompression and recompression disturbances propagating back and forth between the two ends of the exit nozzle. Attendant of this process, each time the decompression disturbance reaches the junction of the nozzle and the vessel, a decompression step is propagated into the vessel as can be observed in the figure for P1. The time base for the vessel pressure history has been shifted to permit comparison of the events in the vessel to be made readily with those in the pipe. Necessarily accompanying the decompression process, a stepwise increase in fluid velocity develops within the vessel and nozzle. The fluid velocity can be calculated using the pressure fluctuations within the pipe and the relation:

$$
u=\frac{\Delta P g}{\rho c}
$$

where $u$ is the particle excursion velocity, $\Delta P$ is the incremental pressure change, $\rho$ is the fluid density, $c$ is the local fluid velocity of sound, and $g$ is the gravitational constant. As $c$ an be seen in Figure 11, the fluid velocity

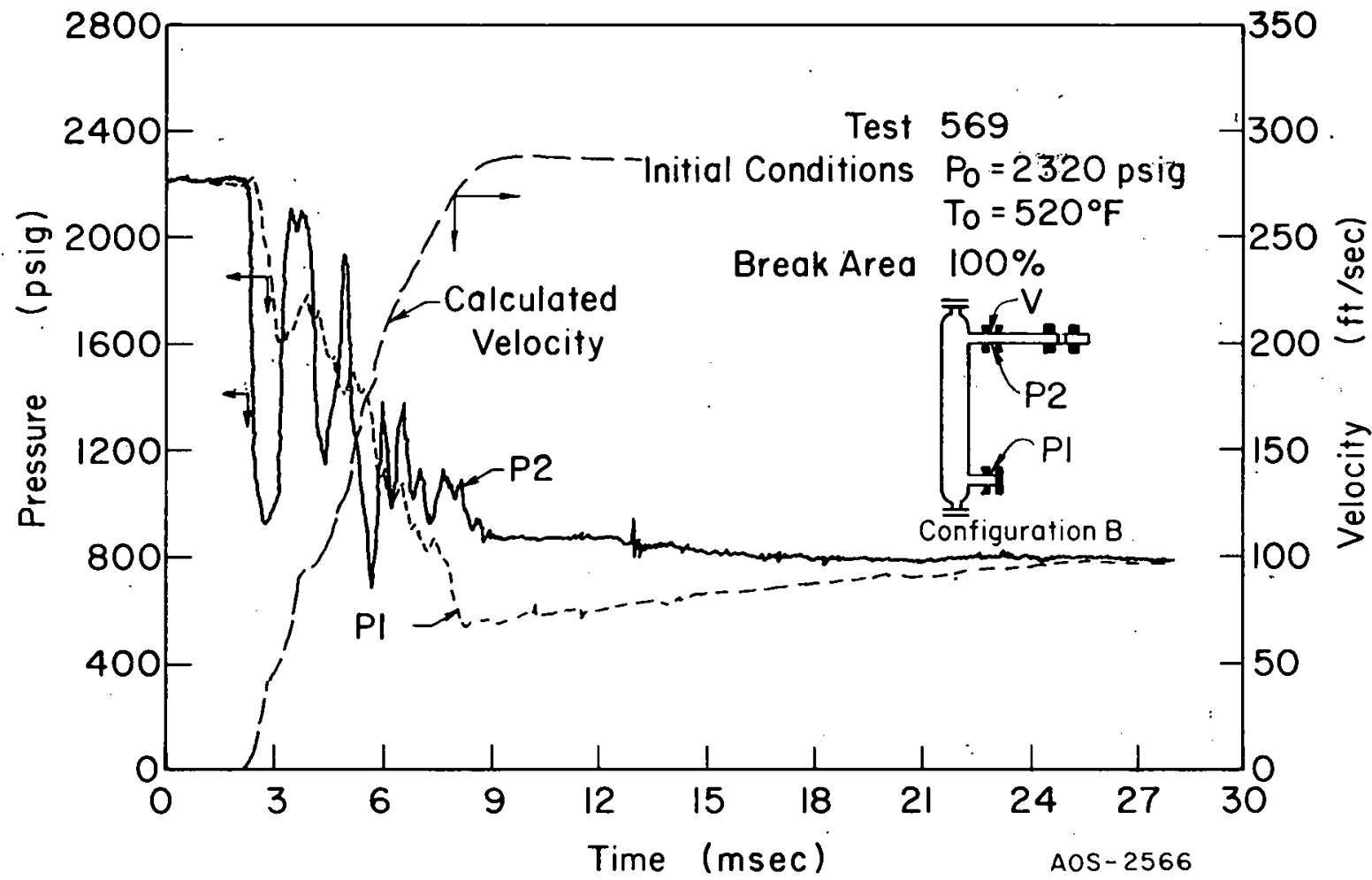

FIG. 11 PLENUM AND PIPE PRESSURIZATION AND NOZZLE FLUID VELOCITY FOR FULL NOZZLE AREA BREAK - - EXIT ACOUSTIC IMPEDANCE MUCH LESS THAN NOZZLE ACOUSTIC IMPEDANCE.

calculated from the pressure fluctuations at P2 reaches nearly $300 \mathrm{ft} / \mathrm{sec}$. The fluctuation frequency of the pipe pressure is representative of the characteristic half-wave organ pipe frequency for that pipe length with $520^{\circ} \mathrm{F}$ water. The fluid velocity. calculated from the pressure data at P2 is not necessarily the maximum fluid velocity attained in the pipe but only represents the velocity calculated by the equation given. The maximum velocity associated with subcooled decompression can be calculated from pressure data if no pressure feedback 
is introduced from the reservoir (vessel) and the pressure data are obtained from a measurement device located at a distance equal to or greater than onehalf wave length from any impedance change. (The wave length is defined as the length of the initial decompression wave and is equal to the product of the fluid sound velocity and the rupture time.)

If a rupture results in a break area such that the acoustic impedance of the fluid at the rupture area becomes essentially equivalent to the characteristic acoustic impedance of the pipe, a marked difference in the system relaxation process occurs compared to that for a fully-open pipe break. Figure 12 for the $10 \%$ break of Test 560 illustrates this case. The first decompression propagating toward the vessel is reversed at the vessel, as in the previous figure; however, as the recompression wave arrives back at the ruptured end of the pipe, subsequent fluctuation processes are terminated as a result of that end of the pipe appearing to have an acoustic impedance similar to that which causes the pipe to appear infinite in length, thus inhibiting any further reflections. The attendant pressure decay in the vessel is seen to be a single initial step followed by a pressure decline rate considerably less than for the fully-open rupture case.

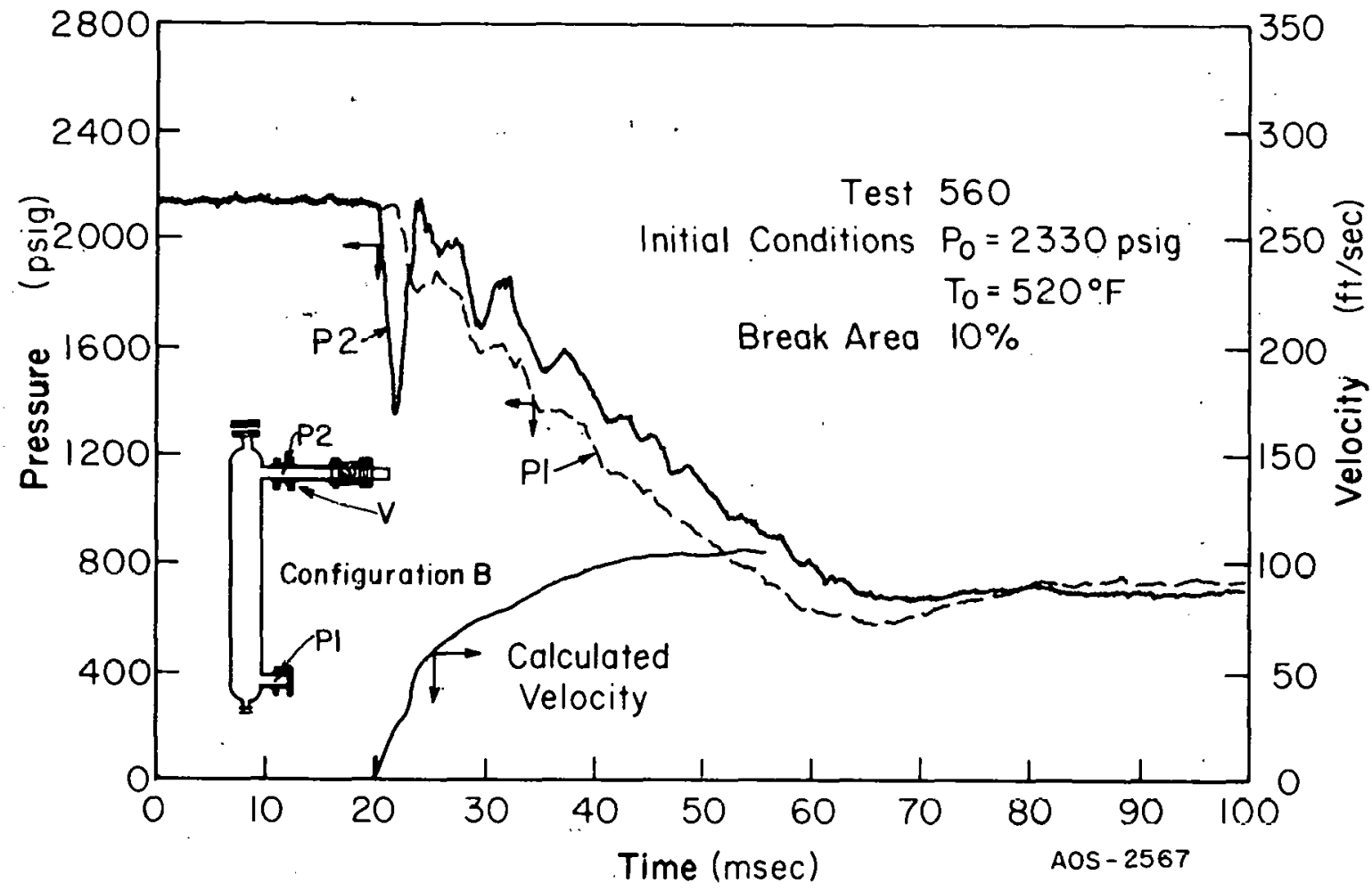

FIG. 12 PLENUM AND PIPE PRESSURIZATION AND NOZZLE FLUID VELOCITY FOR IO\% NOZZLE AREA BREAK - - EXIT ACQUSTIC IMPEDANCE EQUIVALENT TO NOZZLE ACOUSTIC IMPEUANCE.

Although other tests at different initial conditions have shown the pressure decline to be essentially a straight line with no fluctuations, Test 560 at typical PWR fluid conditions was used to illustrate the pipe fluid velocity which is ultimately reached. The calculated velocity is observed to increase essentially as a single step to a value of about $110 \mathrm{ft} / \mathrm{sec}$ or about one-third that for the fully open rupture case. A $10 \%$ pipe area rupture is not quite the correct 
size for representing a characteristic acoustic-impedance rupture at 2300 psia and $520^{\circ} \mathrm{F}$. The break area that would produce such a rupture has been estimated to be between 15 and $20 \%$ of the fully open pipe area.

A very small break results in an acoustic impedance at the rupture point that is higher than the characteristic acoustic impedance of the pipe and the decompression process is further altered as shown in Figure 13. Here the first decompression disturbance, as in the prior cases, reaches the vessel and a recompression wave is sent back along the pipe; however, as the recompression wave reaches the rupture region, the higher terminating impedance of the rupture region requires that the disturbance be doubled in the same polarity as when it arrived at the discontinuity. This doubling, in effect, causes the next disturbance to reach the reactor vessel as a further recompression or essentially causes an increase in pressure over that initially existing within the pipe. The subsequent fluctuations follow this same pattern and the process continues until the flucluations become damped by the resistance in the system at each end of the-pipe. Of importance here is the fact that the frequency of fluctuation is lower by a factor of two for the same pipe length represented by Figure 11. This decrease in frequency is expected because in this case the exit pipe corresponds to a quarter-wave organ pipe having one end effectively open, whereas the other appears closed. Also of significance is the fact that the fluid velocity within the exit nozzle exhibits the initial decompression step; however, the velocity is observed to lessen in magnitude in accordance with the recompression pressure being greater than the initial pipe pressure. In effect, the doubling of the recompression pressure at the rupture location actually causes the fluid within the exit pipe to be periodically decelerated. The final value of velocity is observed to be about $40 \mathrm{ft} / \mathrm{sec}$ as compared to the $110 \mathrm{ft} / \mathrm{sec}$ for the characteristic-acoustic-impedance case and to the $300 \mathrm{ft} / \mathrm{sec}$ for the fully-open pipe area rupture. An important aspect of this behavior is that for a longer exit pipe the initial decompression time is greater. The overpressure has significance with respect to the potential of restarting a crack at the rupture loc ation.

The preceding discussions were given to show the strong influence of the sonic behavior in the exit pipe on the decompression process within the vessel. Several important factors are to be noted in this regard: (a) the decompression rate of the plenum or vessel (which is important to generation of loads) is strongly dependent upon the break size, the ratio of the pipe-toplenum areas, and the distance between the pipe break and the vessel; (b) the break rate needs only to be equal to the time required for about one or two sonic round trips of the fluid within the exit nozzle to be the dominant factor in the subcooled decompression; (c) for large breaks the fluid velocity in the exit pipe may attain a value of several hundred feet per second near the end of the subcooled portion of blowdown; this velocity establishes the velocity at the beginning of the two-phase portion of the decompression in the reactor vessel; (d) the subcooled fluid velocity in the reactor core is a fraction of the fluid velocity in the pipe exit because the decompression waves are attenuated at the various impedance changes associated with area changes at pipe and vessel junctions and plenum and core junctions; (e) a break size approaching a value for which the break region appears as either a characteristic acoustic impedance or a high impedance will cause the system decompression rate to be substantially reduced with an attendant lessening of the fluid velocity. These factors suggest that the differential pressure loads on internals and on primary system components, as 


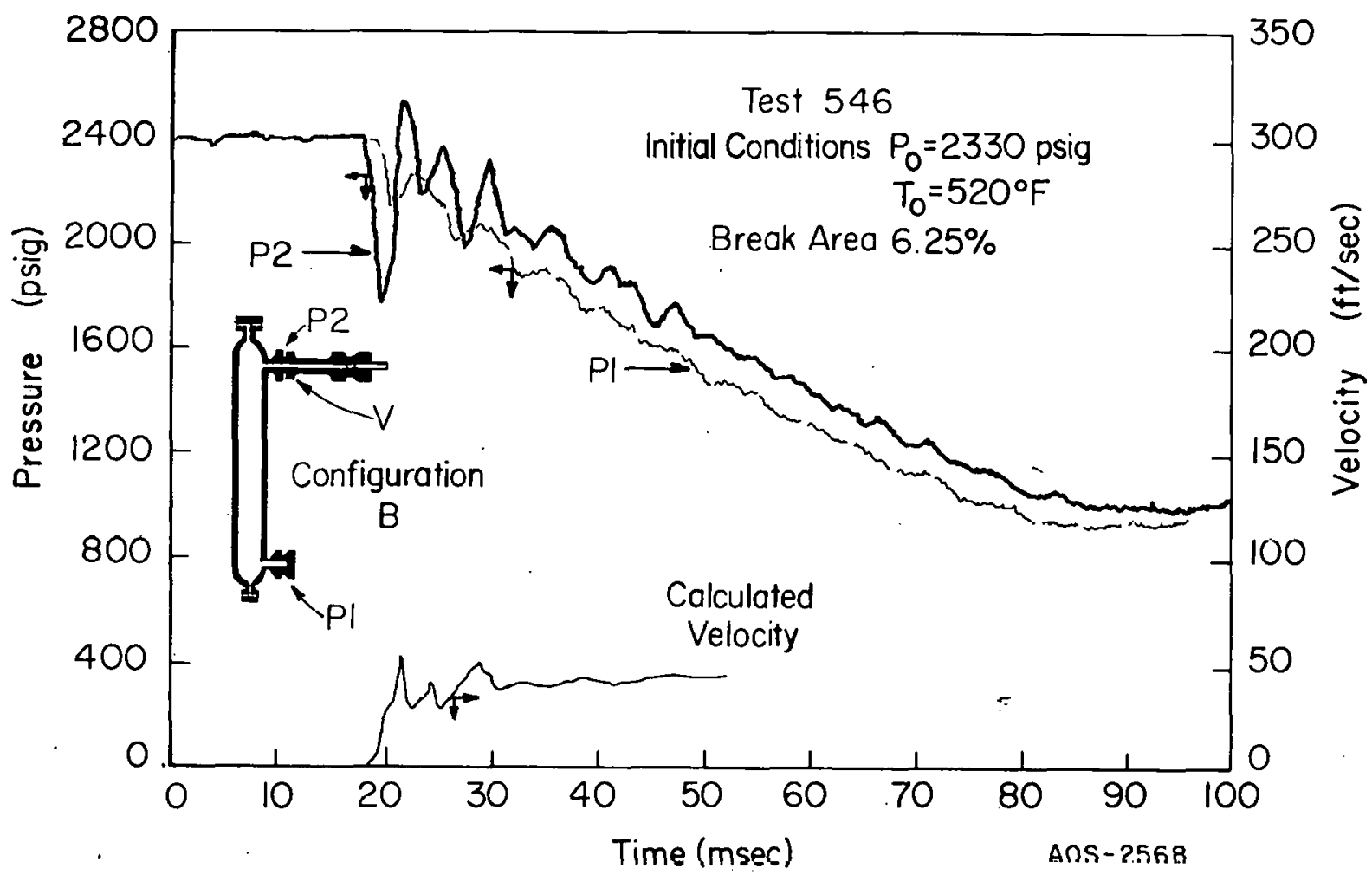

FIG. 13 PLENUM AND PIPE PRESSURIZATION AND NOZZLE FLUID VELOCITY FOR $6.25 \%$ NOZZLE AREA BREAK -- EXIT ACOUSTIC IMPEDANCE MUCH GREATER THAN NOZZLE ACOUSTIC IMPEDANCE.

well as drag loads across reactor vessel internals, will result primarily from large ( $>20 \%$ pipe area) rapid breaks in relatively large pipes wherein the break locations are near the reactor vessel.

The remainder of the discussion is for the subcooled blowdown behavior resulting from large breaks. The discussion is primarily oriented towards the factors which lead to large differential pressure loads being developed across reactor internals and components within the primary system loop.

\subsection{Decompression of Vessel with Connecting Pipe and Internals}

In Figure 14, the system geometry is shown to have internals which characterize a $17 \%$ restriction at the midregion of the vessel and which roughly represent the fluid restrictions for a reactor core. The configuration is an arrangement of two distributed orifice grid plates separated by an array of 30 stainless steel rods $2-\mathrm{ft}$ in length. This particular configuration does not represent an extremely severe change in area within the vessel and, as $c$ an be secn in the figure, the differential pressure resulted primarily from the delay in the disturbance propagating through the 2-ft core region, To be noted is the magnitude and duration of the differential pressure which, although insignificant to the small experimental system, will not be insignificant for full size systems.

The effect of a fully open pipe break is shown in Figure 15 for the case in which the fluid geometry of the core was accentuated toward becoming an inertance volume (large $\mathrm{L} / \mathrm{D}$ ) for the lower plenum much as the exit pipe fluid geometry was an inertance volume for the upper plenum. For this case, 


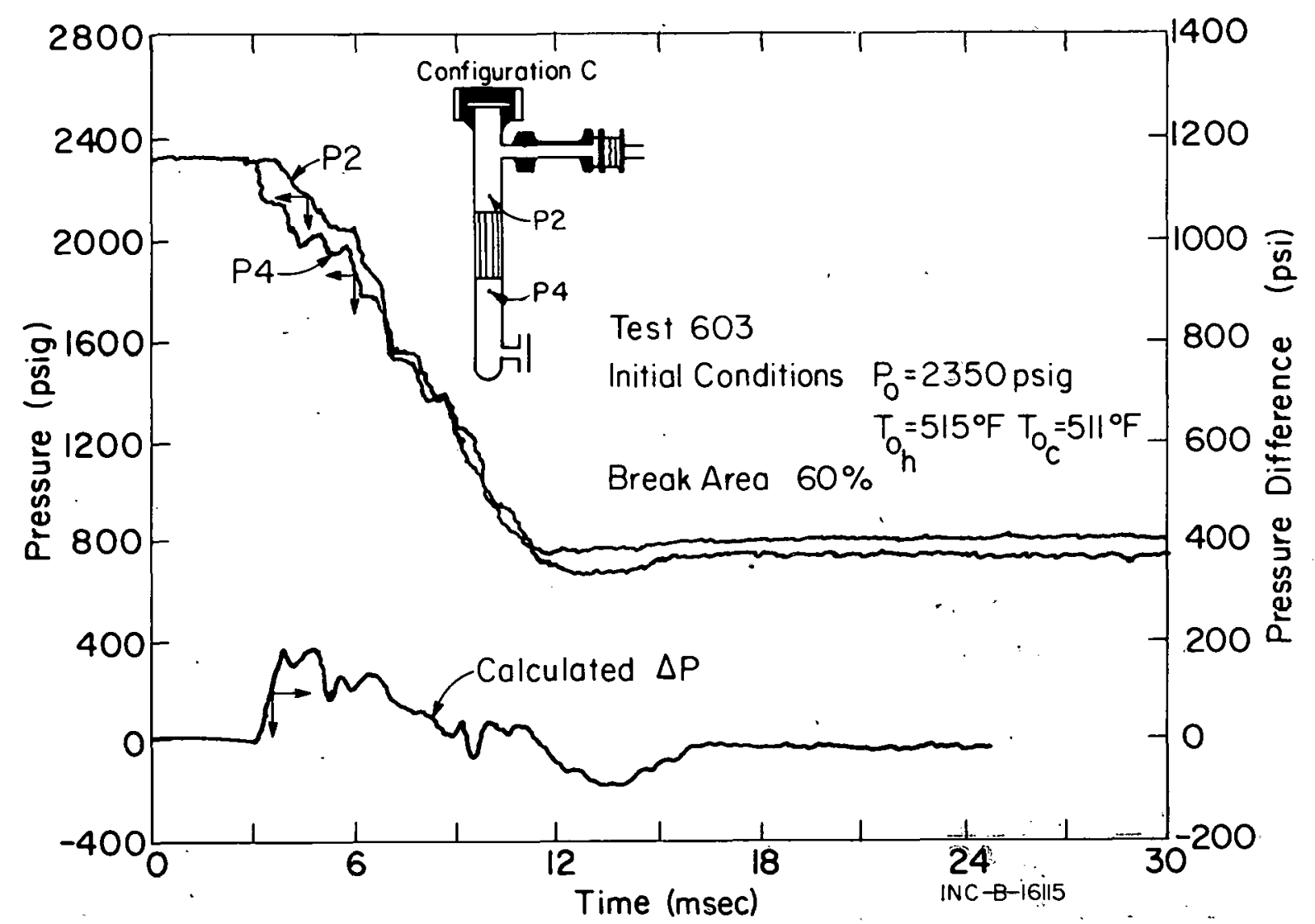

FIG. 14 DIFFERENTIAL PRESSURE FOR SIMULATED LOFT CORE - CORE AREA 73\% OF PLENUM AREA -- CORE ENTRANCE AND EXIT RESTRICTION $17 \%$ OF PLENUM AREA.

since the area available to the fluid in the core is only $6 \%$ of the area available to the fluid in the lower plenum, the lower plenum can be relaxed only through the cyclic sonic processes required to accelerate the fluid within the core. In this particular case the $\Delta P$ across the core is observed to be quite large and extends for nine milliscconds or so.

\subsection{Decompression of Simulated PWR System}

For the core support internals configuration arranged to represent the more complex geometry characterizing current PWR systems, the results are as observed in Figures 16, 17, and 18. This particular configuration is intended to represent the cold-leg break in a PWR of current design in which the core is supported by a barrel. The annulus formed by the barrel and the reactor vessel forms the inlet for the fluid to enter the bottom of the core. The four decompression plots in Figure 16 describe the subcooled decompression histories at two elevations along the support barrel and reactor core region and at the top and bottom of the vessel. These decompression histories are quite predictable with current analysis techniques[15].

The differential pressures developed across the support barrel are observed in Figure 17. 'The top plot illustrates the differential pressure across the support barrel under conditions in which the fluid boundary represented by the barrel has complete integrity through the course of the blowdown. The magnitudes of the pressure excursions are observed to be large and, as will be seen later, represent significant hydraulic loads for the large systems. 


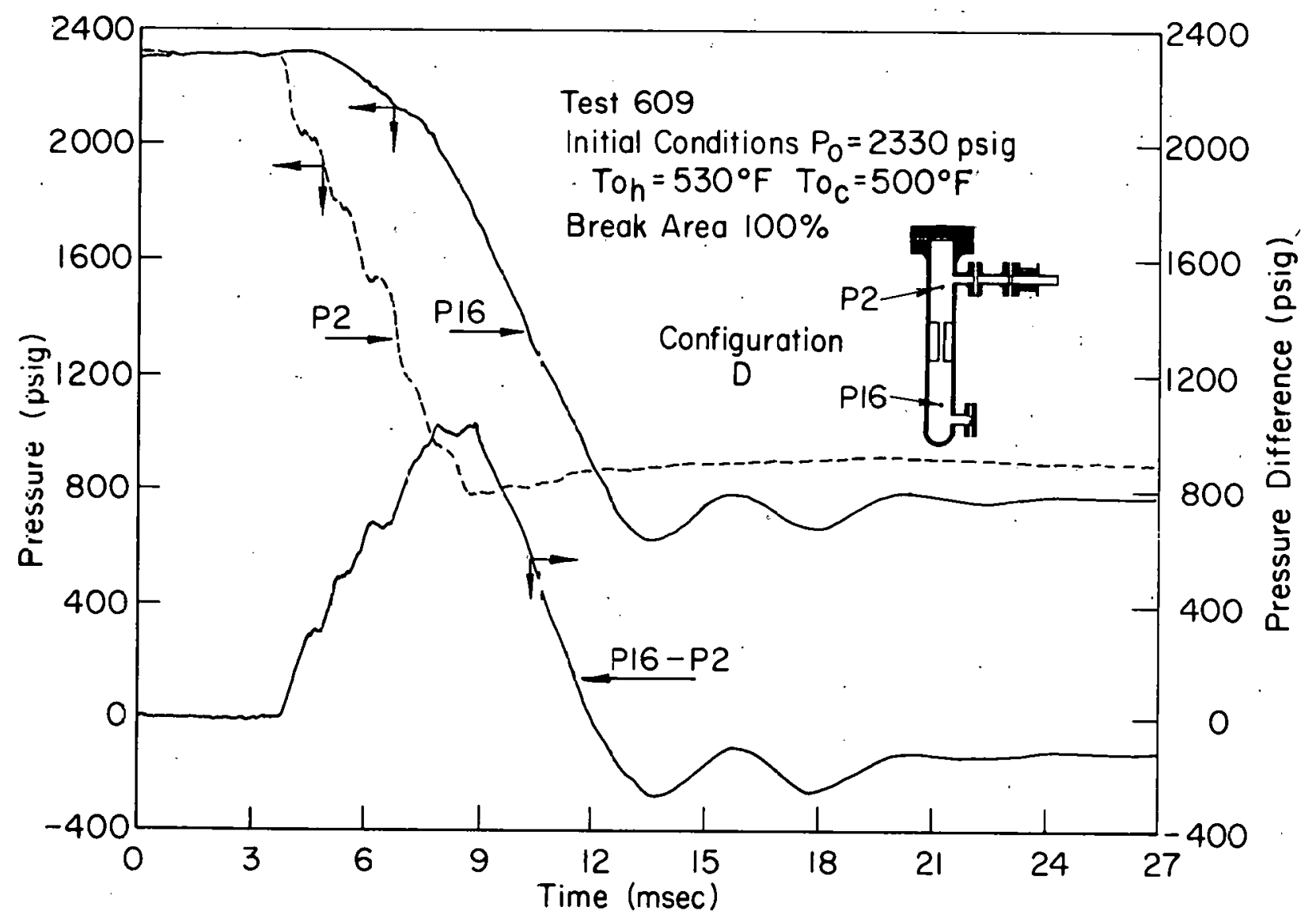

FIG. 15 INERTANCE CORE DIFFERENTIAL PRESSURE -- CORE AREA 6\% OF PLENUM AREA. 
Test 7II. (Oútlat Break)

Initial Conditions $P_{0}=2290$ psig

$\mathrm{T}_{\mathrm{O}_{\mathrm{h}}}=540^{\circ} \mathrm{F}$

$\mathrm{T}_{\mathrm{OC}_{\mathrm{C}}}=505^{\circ} \mathrm{F}$

Break Aréo $30 \%$

$\stackrel{N}{\sim}$

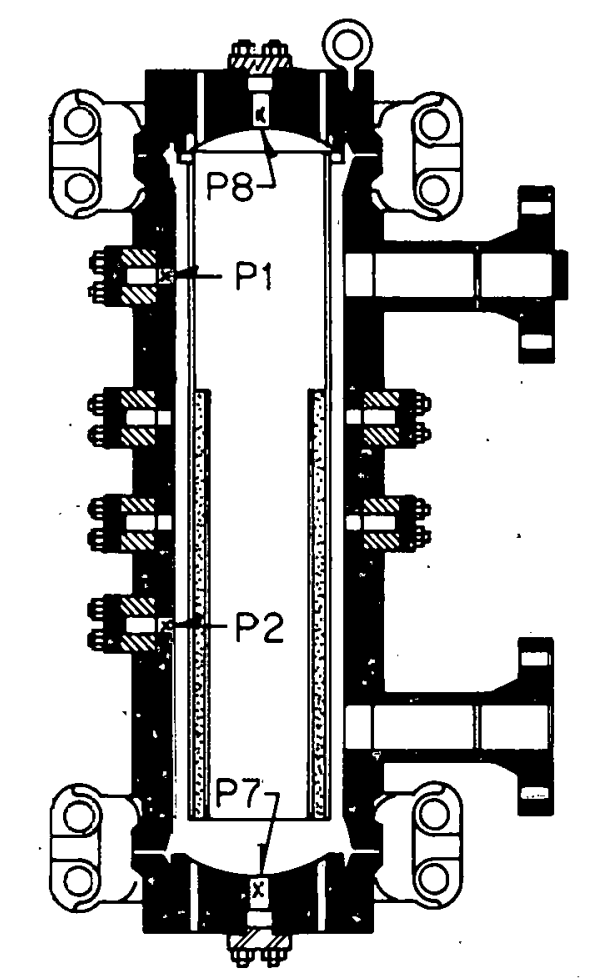

Configuration $\mathrm{F}$

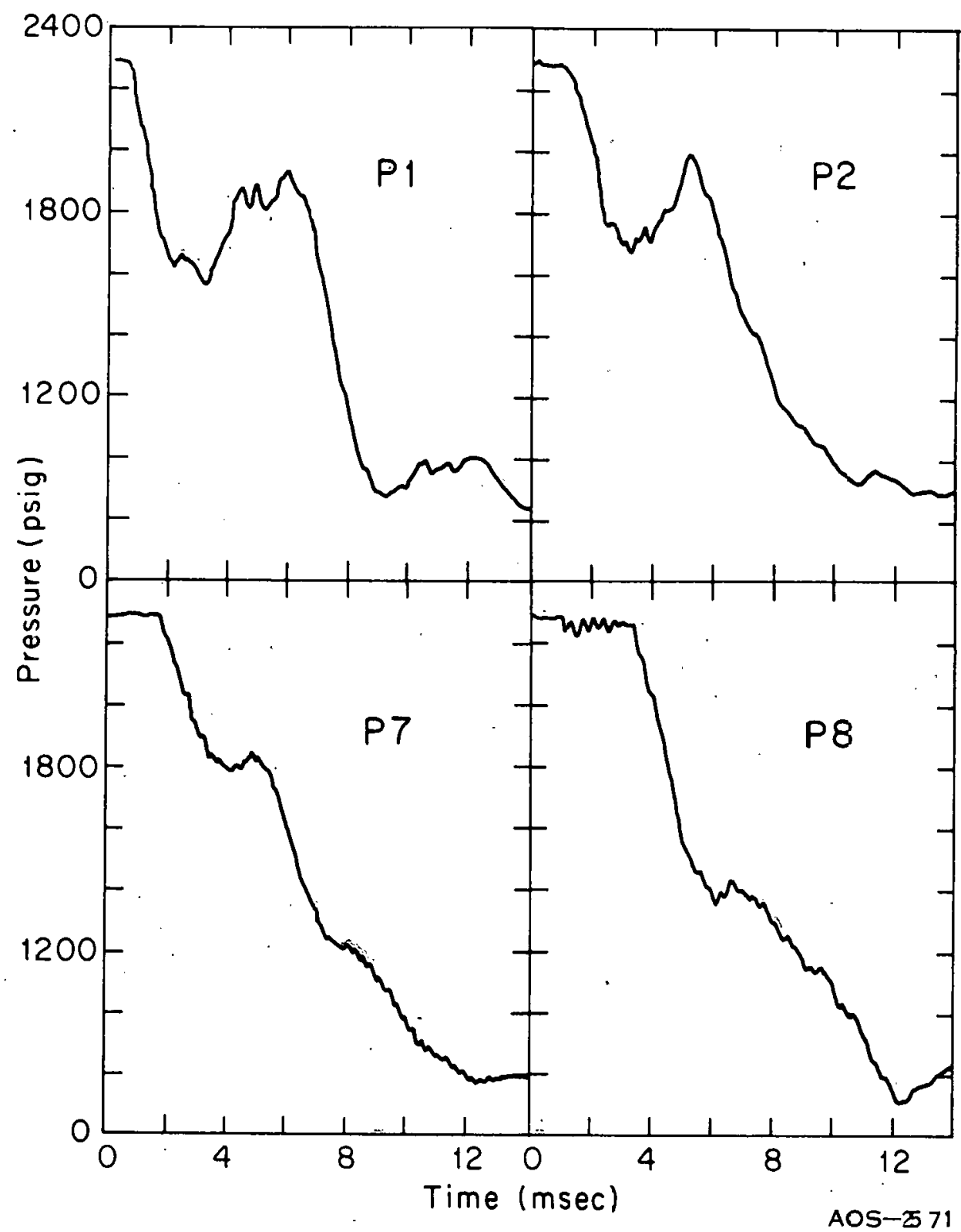

FIG. 16 SIMLILATED PWR INLET ANNULUS AND PLENUM DEPRESSURIZATION. 


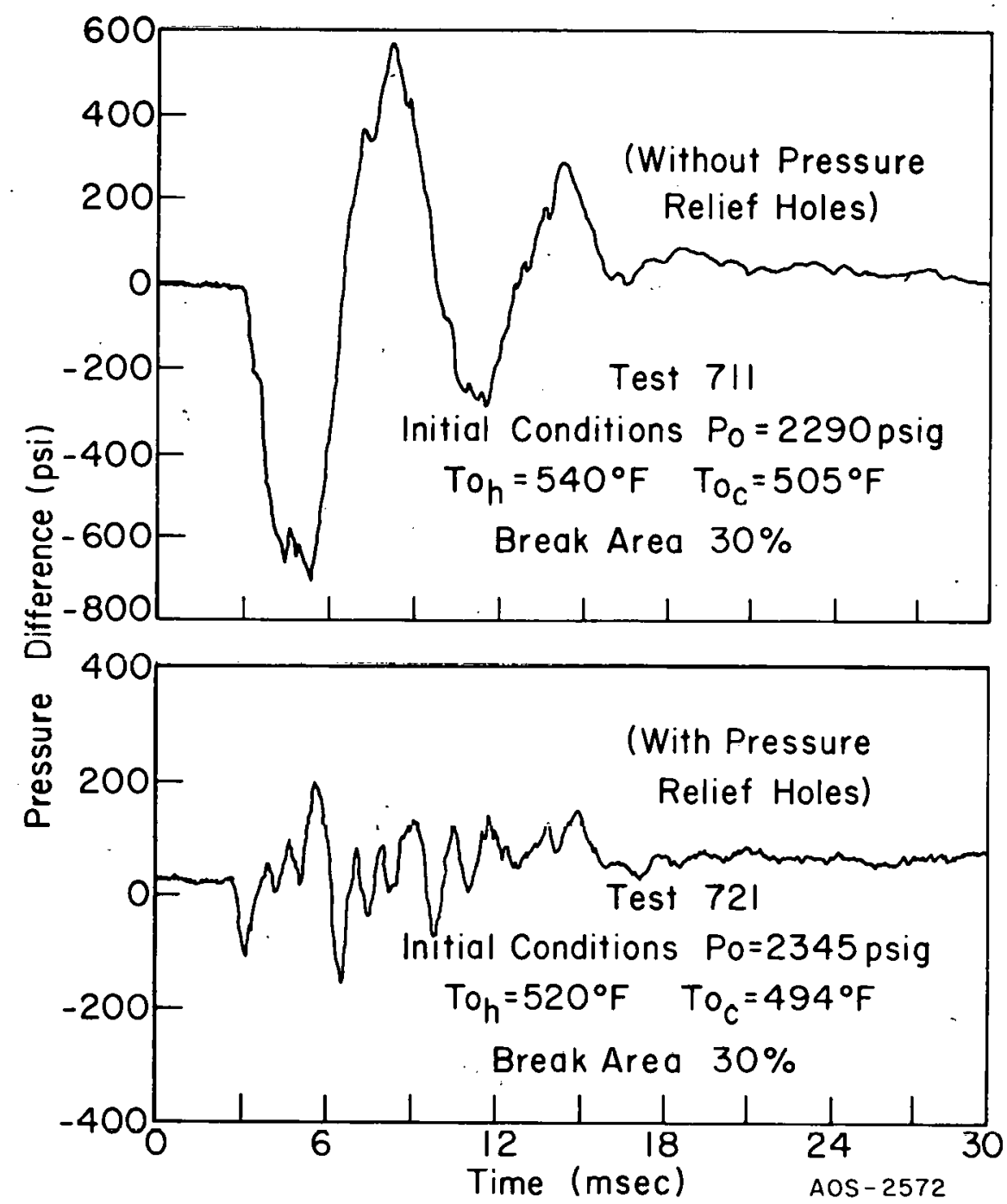

FIG. 17 PRESSURE DIFFERENCE ACROSS CORE SUPPORT BARREL -- BARREL WITH AND WITHOUT PRESSURE RELIEF HOLES -- PB MINUS PI.

The bottom plot represents the pressure difference across the barrel when holes have been provided within the barrel to act as a pressure relief for the upper plenum. At least one current commercial design provides for swing check valves in the upper plenum such that a cold leg break will eliminate a large barrel $\Delta \mathrm{P}$ as well as the core $\Delta \mathrm{P}$. The difference in differential pressure levels for the two cases is readily seen in the figure.

Figure 18 similarly illustrates the pressure differential across the reactor core with and without pressure relief holes in the upper barrel. The effect of the holes upon decreasing the core pressure differentials is again readily observed.

Another degree of complexity in the fluid envelope geometry is shown in Figure 19. This figure illustrates the decompression histories at points just upstream and downstream from the plenum of a simulated heat exchanger for a single primary coolant loop attached to a reactor vessel without reactor intermals. In the configuration shown, the decompression disturbance initiated at the rupture must divide at the tee causing the magnitude of the decompression 


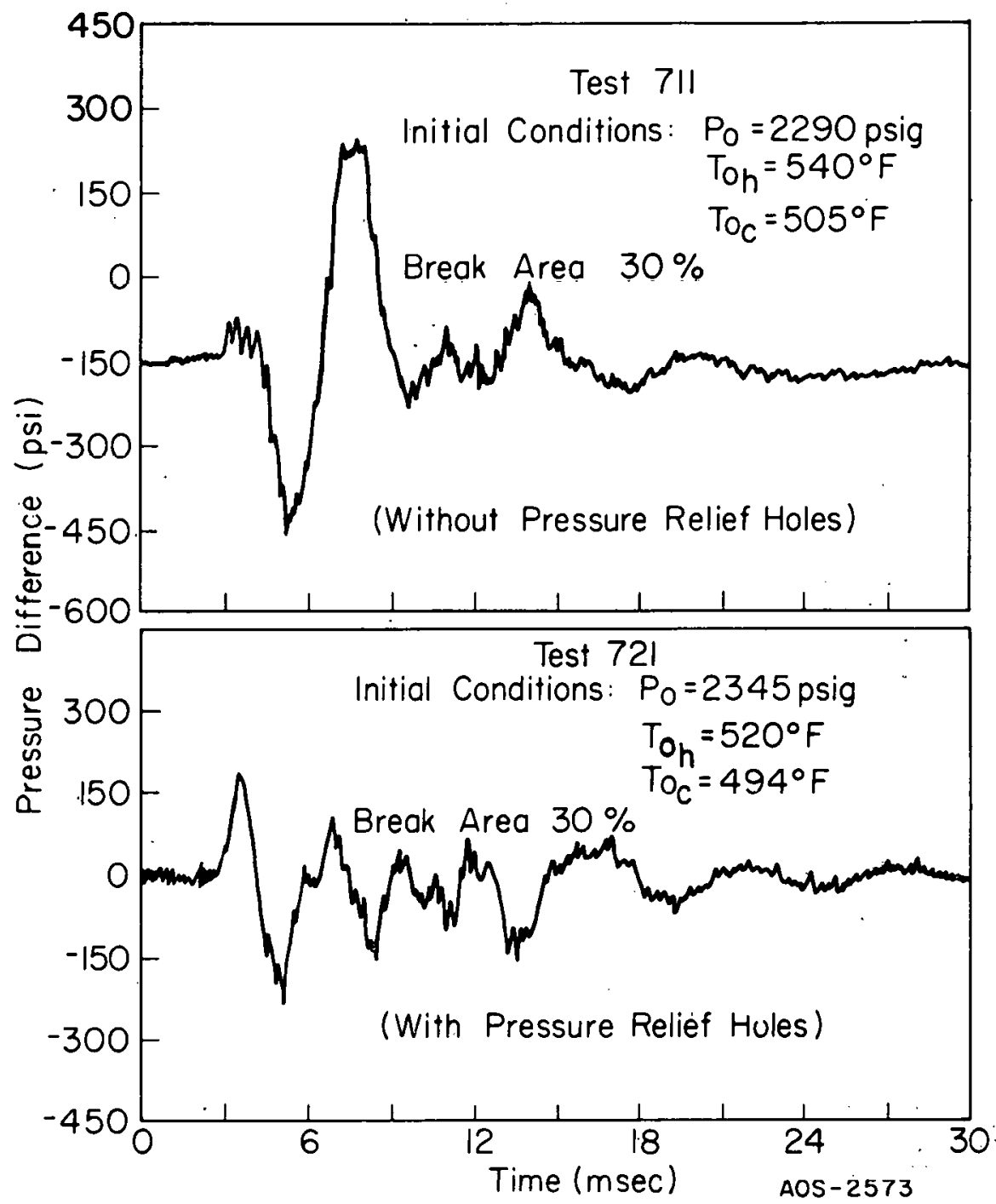

FIG. 18 PRESSURE DIFFERENCE ACROSS REACTOR CORE -- BARREL WITH AND WITHOUT PRESSURE RELIEF HOLES -- P8 MINUS P7.

step that propagates beyond the tee into the reactor vessel and on around the coolant loop to be approximately two-thirds of that initiated at the rupture location. Figure 19 also shows the pressure differential developed across the simulated heat exchanger. This pressure differential when scaled to systems of large dimensions, will produce significant loads on tube sheets and tube sheet supports. 


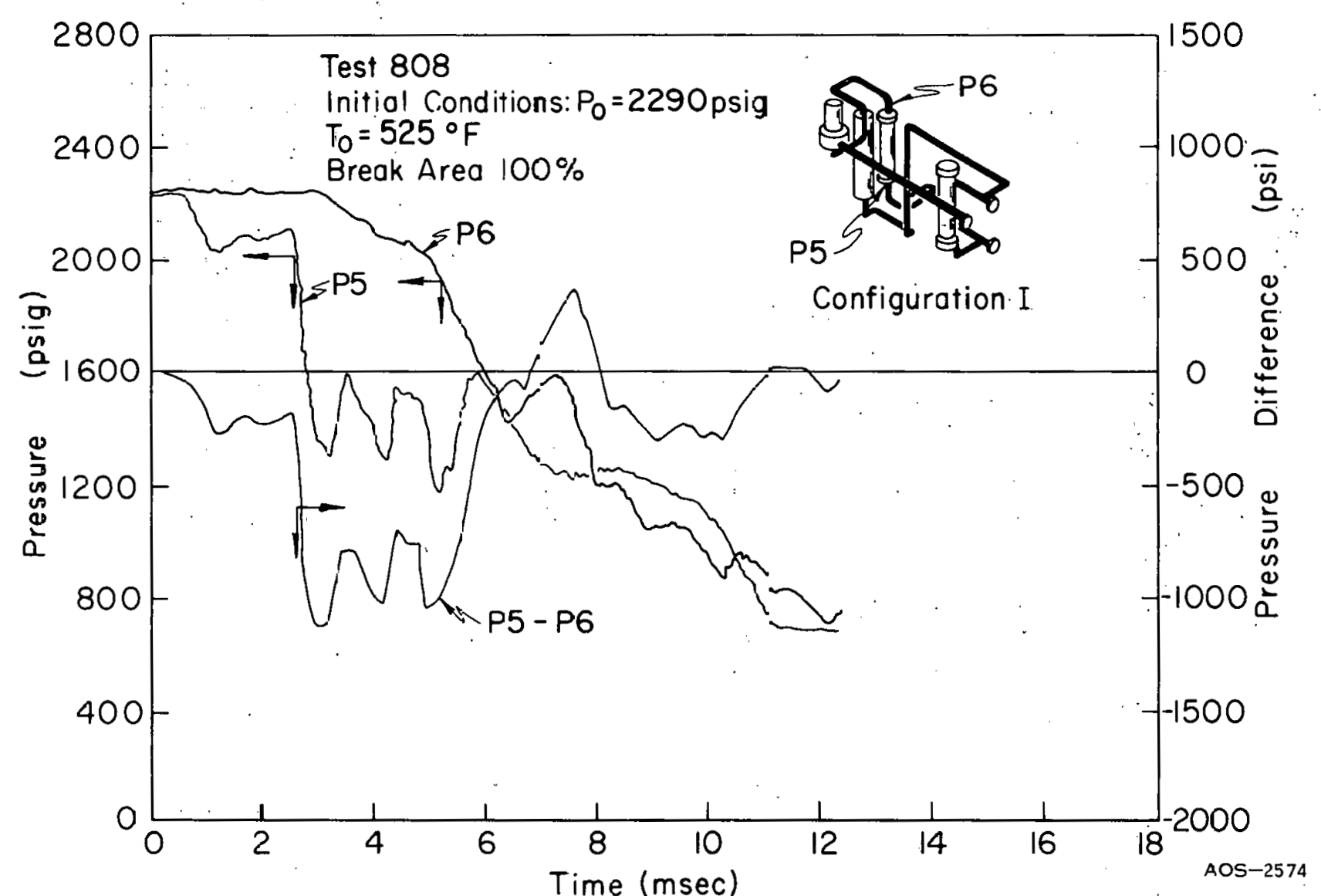

FIG. 19 SUBCOOLED DECOMPRESSION HISTORIES AT EACH END OF THE SEMISCALE HEAT EXCHANGER AND THE RESULTING PRESSURE DIFFERENTIAL HISTORY. 


\section{RESULTS FOR TWO-PHASE DECOMPRESSTON BEHAVIOR}

For the two-phase decompression behavior, the primary areas of interest are (a) those aspects of the geometry of the fluid envelope that control the two-phase decompression process, that is, break size, elevation of exit nozzle, internal fluid restrictions, and primary system loop; and (b) those aspects of the fluid behavior which, in conjunction with the fluid envelope, affect the leak flow rate, phase separation, water remaining, and thermal stress.

Since the two-phase decompression and phase separation processes are highly nonlinear and highly sensitive to such factors as the length-to-diameter ratios of the fluid path, entrance geometry, fluid restrictions, surface-tovolume ratios, and number of nucleation sites within the liquid and on surfaces, experimental conditions are difficult to repeat and also difficult to measure.

One of the particularly difficult problems is that of making accurate pressure measurements in the adverse environment of a flashing fluid. Attendant to the fluid decompression is a transient decrease in temperature that rapidly causes all structures and objects that were originally at the initial operating conditions to act as heat sources. to the liquid such that the liquid may undergo nucleate boiling. This high heat transfer from the structures to the liquid in turn causes preferential cooling of the objects and structures and results in dimensional distortions which lead to uncertainty in the measurements during the latter stages of the two-phase decompression.

Accurate pressure measurements in the early two-phase regime are important for recording the effects of pressure differences across various flow restrictions, particularly for future tests incorporating a hot-leg, cold-leg temperature difference. The importance of these measurements motivated the development of a subroutine in the data processing which compares a temperature-pressure relationship at a given location in the system with the equilibrium saturation line on a pressure-temperature (P-T) plot. The upper portion of Figure 20 is one form of such a comparison of a selected test temperature and pressure for the total excursion. In this figure a subcooled condition, observed to exist at the beginning of the decompression, passes without temperature change to the left of the equilibrium saturation line. The temperature and pressure then decay with a slight nonequilibrium condition existing early in two-phase decompression and approach equilibrium as atmospherlc conditions are reached at the end of blowdown. This technique of comparing experimental data to equilibrium conditions is extremely valuable in assessing the performance of the measurement systems. The lower portion of Figure 20 is another form of displaying the same information. For purposes of illustrating the current data processing technique, the actual computerproduced plots printed by the data processing routine are shown in Figure 20 and in Figure 21 which is discussed in the following section. Only the legend and curve identification and the sketch of the experimental configuration have been added.

\subsection{General Two-Phase Decompression Behavior}

Figure 21 represents the fluid pressure and temperature history for a test employing a vessel void of internals (Configuration B). The temperature and pressure histories for this test are typical of results over a wide range 

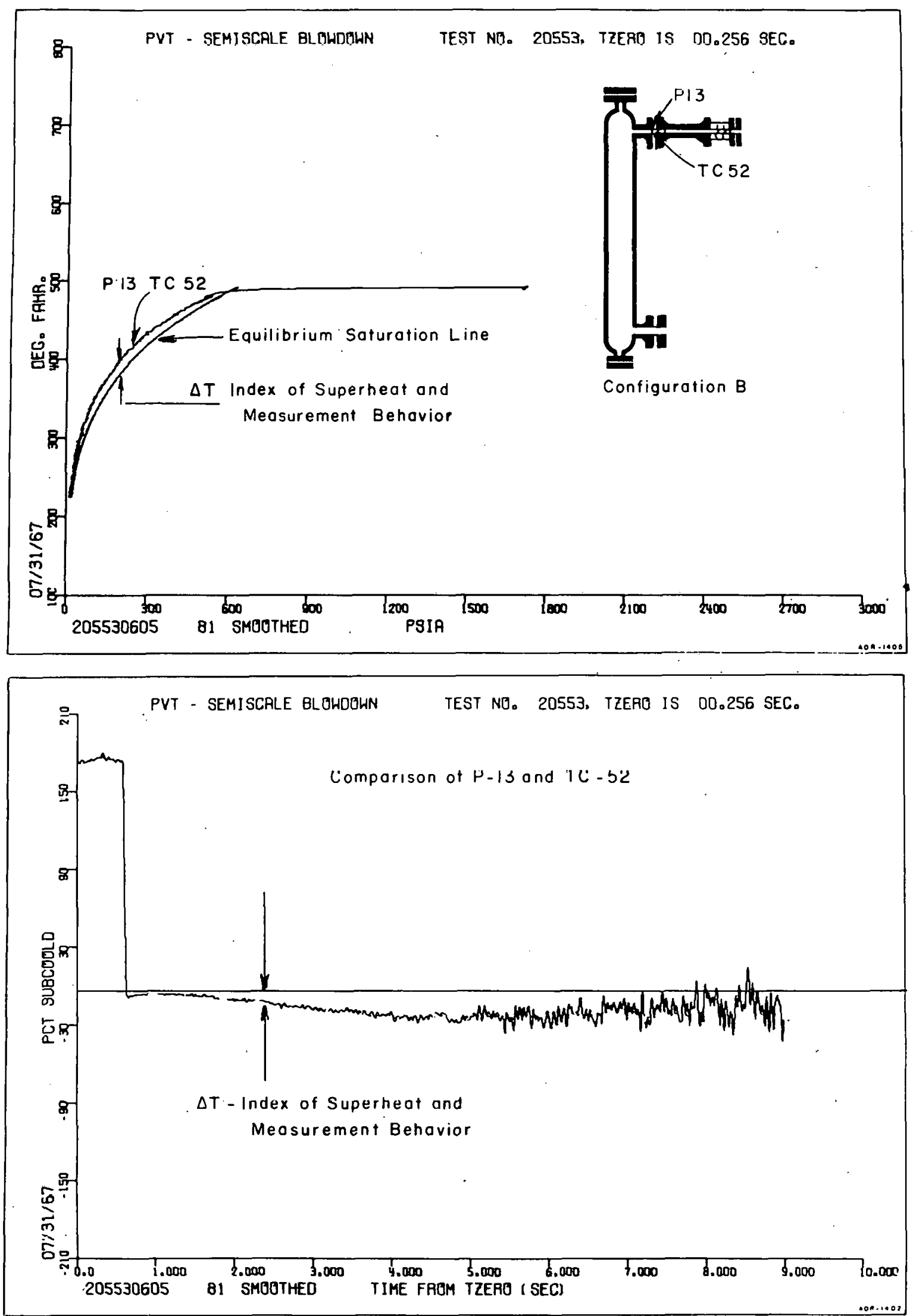

FIG. 20 METHODS FOR EVALUATING FLUID TEMPERATURE AND PRESSURE IN RELATION TO EQUILIBRIUM CONDITIONS PRESCRIBED BY STANDARD STEAM TABLES AND ALSO AN INDEX OF MEASUREMENT SYSTEM PERFORMANCE. 

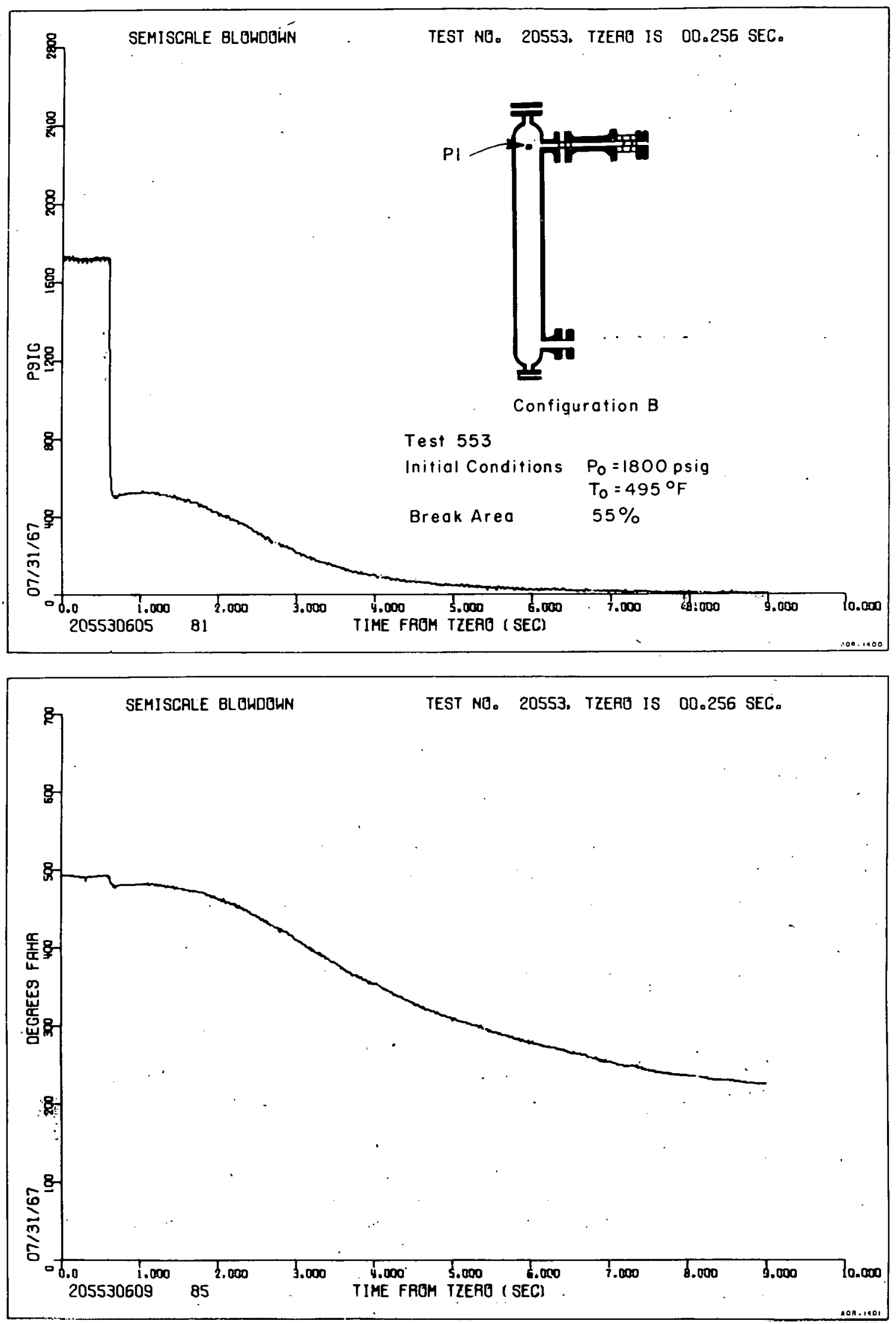

FIG. 21 TWO-PHASE VESSEL PRESSURE AND TEMPERATURE HISTORY. 
of break sizes and initial conditions of temperature and pressure. The pretest initial temperature is about $495^{\circ} \mathrm{F}$. The equilibrium saturation pressure corresponding to this temperature is about 607 psig. The observed saturation pressure following the subcooled decompression, however, is about 520 psig and the observed temperature about $480^{\circ} \mathrm{F}$. If the pressure-temperature relation indicated by Figure 21 is compared through use of the technique of Figure 20 to the equilibrium saturation curve in a standard steam table, a superheat condition of from 5 to $15^{\circ} \mathrm{F}$ will be evidenced, depending on the blowdown rate. This small temperature difference indicates the near equilibrium relation of temperature to pressure.

The pressure and temperature undershoots observed at the termination of the subcooled decompression indicate that nonequilibrium conditions exist. This nonequilibrium condition, which is considered to be a result of the volume of water in the exit pipe being highly accelerated during subcooled decompression, allows withdrawal of fluid from the vessel more rapidly than the fluid $c$ an flash and restore the pressure. These particular phenomena of pressure and temperature undershoots, although important to the early initiation or extension of DNB in the core, may be unique to small scale systems in which decompression rates can exceed the flashing rates, or may be the result of measuring localized fluid conditions rather than the bulk conditions.

Figure 22 illustrates the decompression history for two tests of nearly equivalent initial test conditions but for different nozzle elevations. The figure shows the depressurization process to be relatively insensitive to the nozzle location, particularly for the subcooled decompression process. Factors exist, however, in the two-phase regime that should be considered in light of the small but distinct differences in behavior that are observed. The general undershoot of pressure at the onset of the two-phase regime appears to be similar for both break locations; however, the pressure for the top break case increases abruptly after flashing is established compared to that for the test with a bottom nozzle. This difference in pressure increase following the undershoot is not that which would normally be expected in that the equilibrium saturation pressure for the top break case is about $800 \mathrm{psig}$, whereas for the bottom case it is about 945 psig. The near recovery for the top break case as compared to the apparent lack of recovery for the bottom case deserves further consideration.

The abrupt pressure rise at about $0.7 \mathrm{sec}$ for the top break case, has been correlated with the mixture level in the vessel having dropped below the elevation of the exit nozzle. At this time the rate of liquid expulsion is reduced thus the vapor extends into a volume that has now decreased its rate of expansion. The vessel pressure rises until the efflux rate exceeds the phase separation rate at which time decompression is again restored.

For the top break case, the two-phase mixture entering the top nozzle increases in quality considerably earlier in the blowdown than that entering the bottom nozzle for the bottom break case. The mass efflux rate is thus less for the top break case than for the bottom break case early in the blowdown. The greater amount of liquid remaining for the top break case consumes greater volume and, therefore, lessens the volume for the two-phase mixture, thus aiding in the restoration of the pressure to the equilibrium saturation condition. 


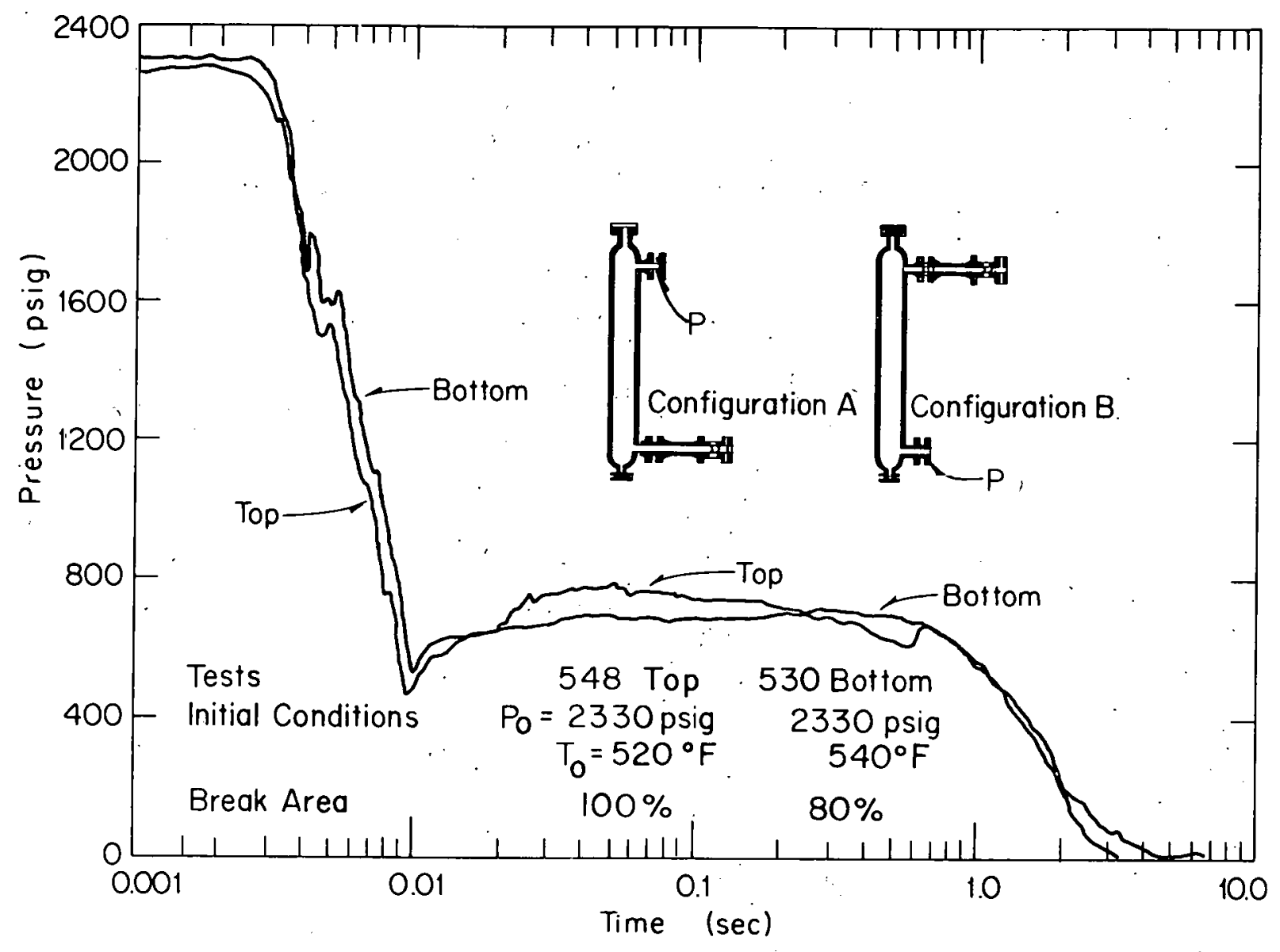

\begin{abstract}
FIG. 22 COMPARISON OF VESSEL PRESSURE HISTORIES FOR TOP AND BOTTOM BLOWDOWN CONFIGURATIONS:

The decompression for the bottom break case is almost a classical homogeneous process (for the large break size considered here) in that the mixture leaving the nozzle is very low in quality because the liquid that does not flash is swept out, thereby leaving a considerably increased volume (compared to that for the top break case) into. which the vaporized fluid can expand. Another factor to consider is that for the top blowdown the fluid that does flash must first go through the vapor phase prior to being exhausted from the system, whereas for the bottom break case much of the fluid containing stored energy is carried out prior to vaporization.
\end{abstract}

The top blowdown tests, which exemplify the difference between the fluid expansion in top and bottom blowdowns, are those with break sizes equal to or less than $30 \%$ of the fully open nozzle area. The smaller break sizes increase the total depressurization time and the time to allow phase separation to occur in the vessel. Consequently, the plume developed at the nozzle exit plane in top blowdown tests, especially small break cases, consists of higher quality fluid than the plume for bottom blowdown tests.

. The plume behavior is confirmed by a comparison of the stagnation pressures generated during top and bottom blowdown tests at comparable initial fluid conditions, as shown in Figure 23. The stagnation pressures plotted in this 


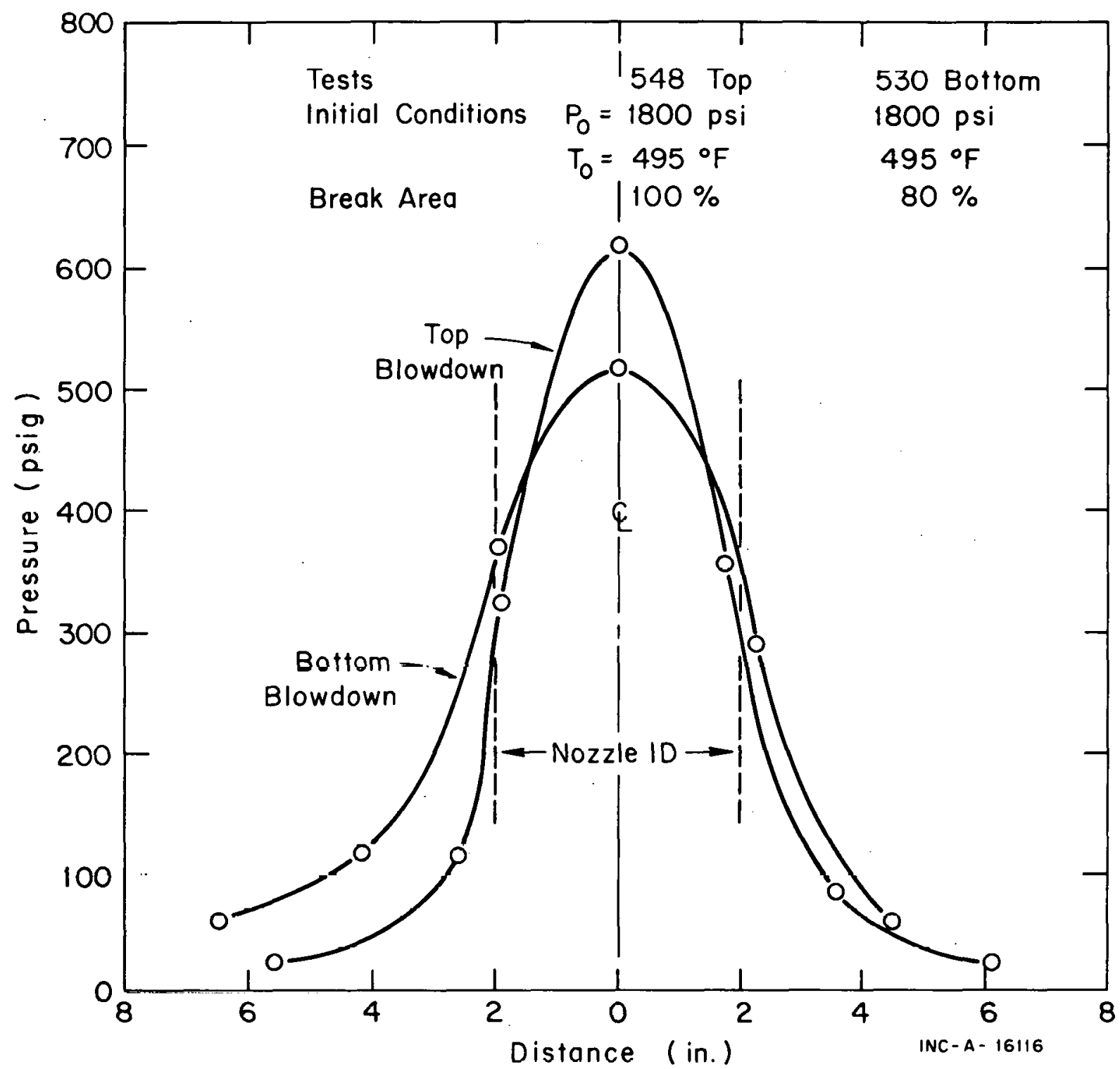

FIG. 23 STAGNATION PRESSURE ONE PIPE DIAMETER FROM NOZZLE EXIT 500 MSEC AFTER TOFOR TOP AND BOTTOM BLOWDOWN TESTS.

figure were determined by dividing the experimentally measured forces by the area of the device measuring the force. In comparison to the pressures for a top blowdown, the stagnation pressures for the bottom blowdown are seen to be lower at the center of the blowdown nozzle, but are higher at the periphery and beyond, apparently because the plume has expanded more.

Figure 24 illustrates the effect of break size on the decompression process. The same general phenomena as observed in Figure 22 are exhibited, including the undershoot and the abrupt pressure change when the liquid level passes below the elevation of the exit nozzle. The greater pressure undershoot observed for the $100 \%$ break is not unexpected bec ause the subcooled decompression rate has an attendant nozzle fluid velocity considerably greater than that for the smaller break case in which the flashing rate can more easily keep up with the efflux rate. 


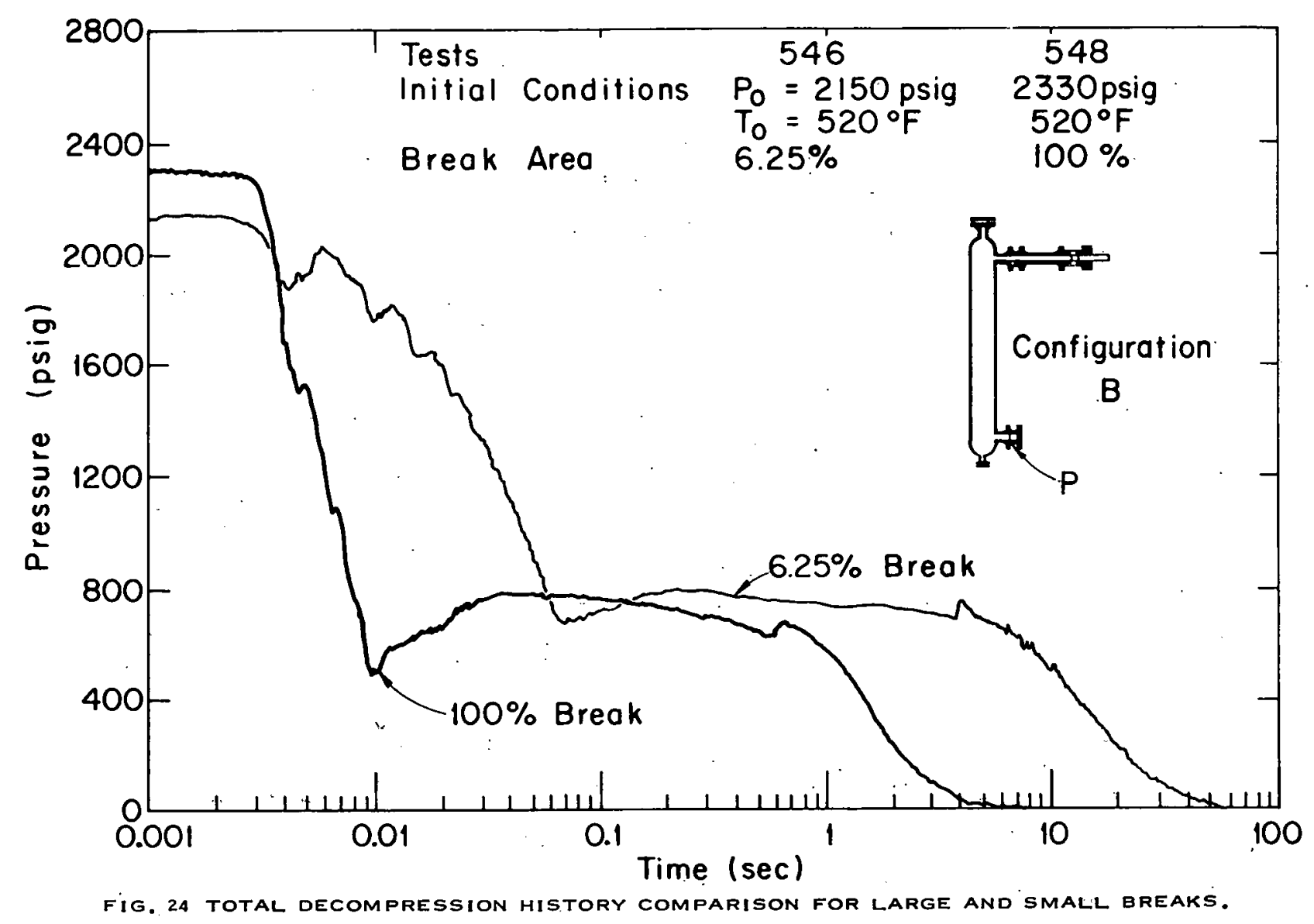

Figure 25 illustrates the total decompression process for the case in which internals have been added within the vessel. For this particular test the internals were intended to overemphasize the length-to-area ratio, or impedance effect of the reactor core, in order to permit the subcooled core pressure difference discussed in the subcooled section to be studied. Important to note, however, is the behavior of the pressure in the early part of the saturated regime with respect to extended duration core loads. The hot leg pressure is observed, following subcooled decompression, to recover to nearly the initial saturation condition. The cold leg pressure, however, is seen to decrease below the hot leg pressure, although not to the saturation condition for the cold leg. Of significance is the long time lapse, nearly $200 \mathrm{msec}$, until flow is reestablished, when the greater pressure in the lower plenum forces fluid through the core and out the break. The time lapse is a result of the low velocity of sound that exists until the initial fluid in the core region flashes and expands to reasonable quality. This low velocity of sound inhibits the communication between the two plenums and a significant period of time is required before the pressure can recover from the apparent anomalous pressure reversal.

Figure 26 is a comparison of the pressure history for the semiscale vessel, with and without the primary loop, and is included to show the greater pressure behavior difference. 


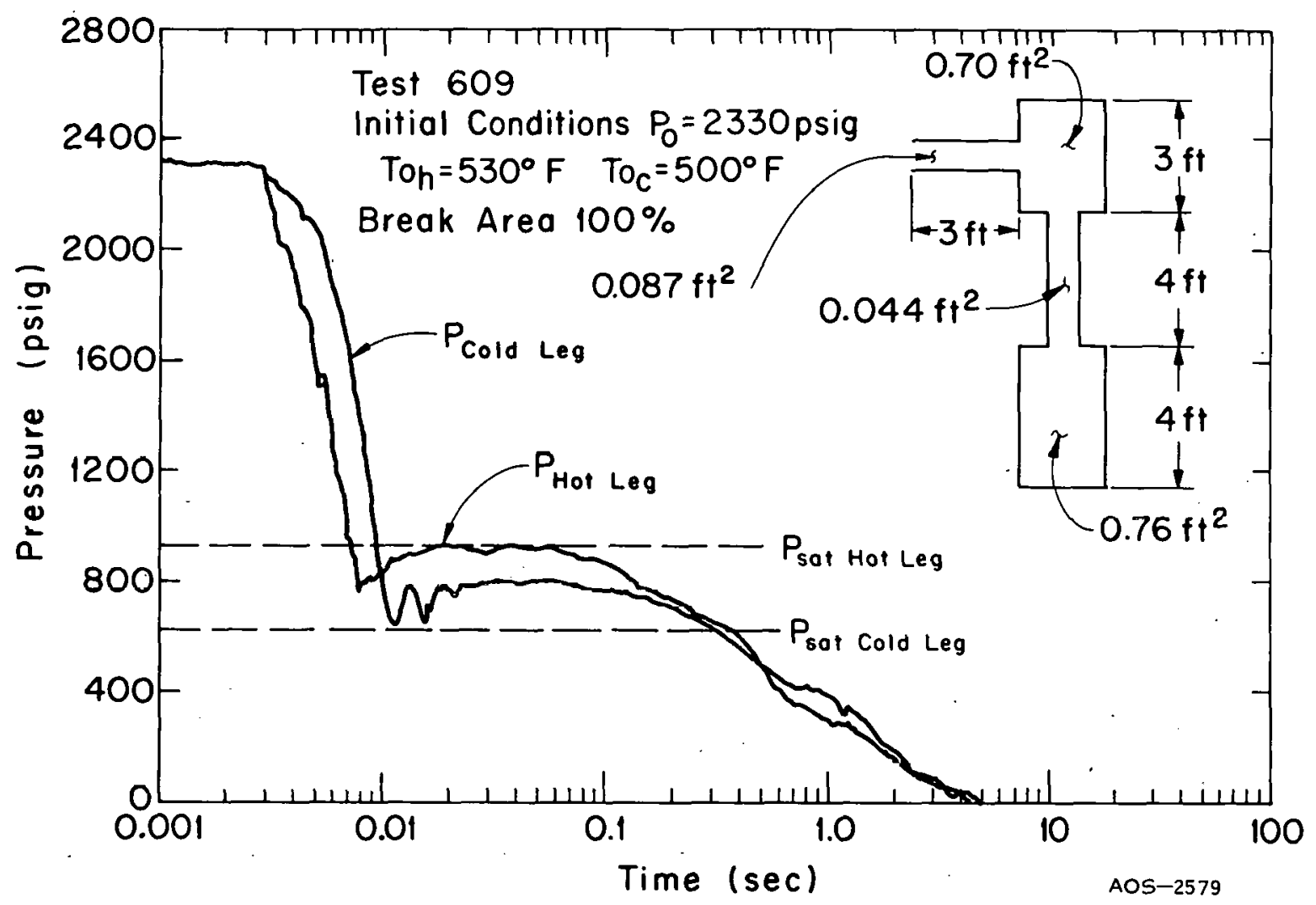

FIG. 25 FLUID DECOMPRESSION IN A VESSFL WITH ACCENTUATED HYDRAULIC RESTRICTION.

\subsection{Factors Affecting Coolant Decompression Within the Vessel}

For the subcooled decompression, the sonic relaxation phenomenon was cited as strongly influencing the mass efflux rate from the system. Similarly, for the two-phase dccompression, the behavior of the fluid at the puinl at which the vessel fluid enters the exit pipe, and at the choking plane near the end of the pipe, affects the mass efflux rate from the system. The mass efflux rate, in turn, affects the system decompression rate, core cooling, and water remaining.

With regard to behavior of the fluid entering the exit pipe and the effects of the geometry of the pipe on the leak flow rate, some important observations can be made from the array of tests conducted to date. For the experiments conducted in the test series thus far, the entrance to the exit pipe from the vessel would be classed as being sharp edged. The fluid behavior has been postulated as a function of distance along the pipe; that is, the vena contracta region, the two-phase expansion region, the friction pressure drop region, and the exit choking region[16]. Although this theoretical work has primarily dealt with exit pipe fluid behavior under subcooled conditions at the entrance of the pipe, the behavior observed for the majority of the semiscale blowdown experiments with two-phase mixture entering the exit pipe generally supports the theoretical description for nozzle entrance fluid conditions. However, certain tests have shown evidence of choking at the entrance to the pipe at the same time choking is observed at the exit of the pipe. Figure 27 illustrates these observations. 


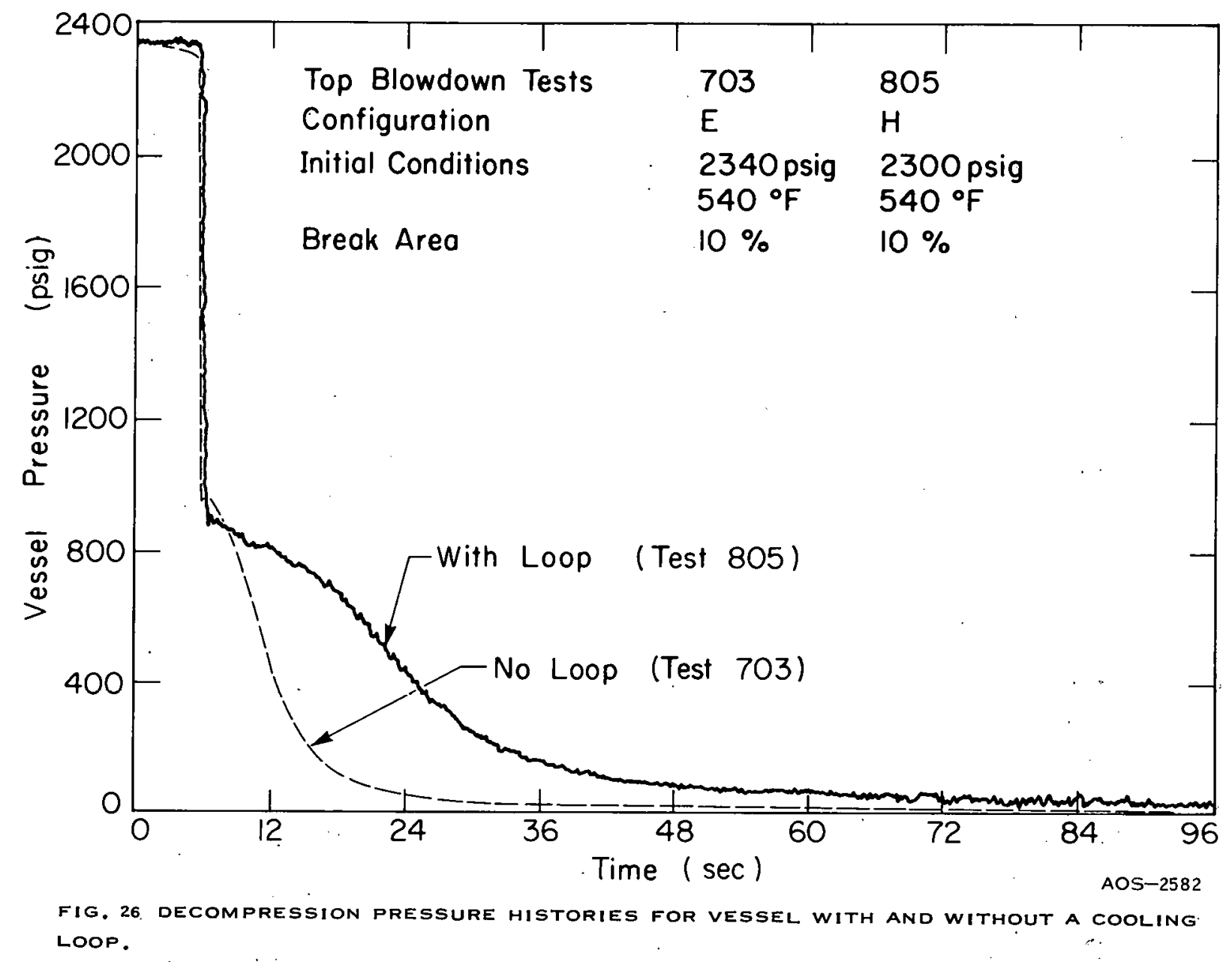

The upper portion of Figure 27 shows, through pressure measurements along the pipe, the type of theoretically postulated behavior in which the system mass efflux is controlled at the choking plane downstream of the expansion region. Here the pressure within the vessel, $\mathrm{P} 4$, and within the expansion region of the exit pipe, P9, are, for all practical purposes, observed to be the same with the exception of a slight pressure drop due to friction. A pressure measurement, P8, made one diameter downstream from the entrance plane of the exit nozzle shows a very severe vena contracta pressure drop to near atmospheric conditions after one second. The pressure transducer, $\mathrm{P} 12,1 \circ \mathrm{c}$ ated one inch upstream from the exit plane, shows a severe drop compared to P9",indicating choking downstream of the orifice plate as well as the exit plane. The P12 pressure movement is considered to be erroneous after one second.

The lower portion of Figure 27 illustrates the other cases in which the fluid entering the exit nozzle initiated choking early in the course of the decompression. By using an average critical pressure ratio of $0.7[17]$, the pressure history from P9 suggests that choking was established at the nozzle entrance and persisted through the major portion of the blowdown. Further, P12, which was operational throughout this test, indicates choking also existed at the exit plane until approximately two seconds, at which time the choking front progressed up the pipe past P12. P8, the pressure at the vena contracta, is observed to behave similarly to the vena contracta pressure history in Figure 


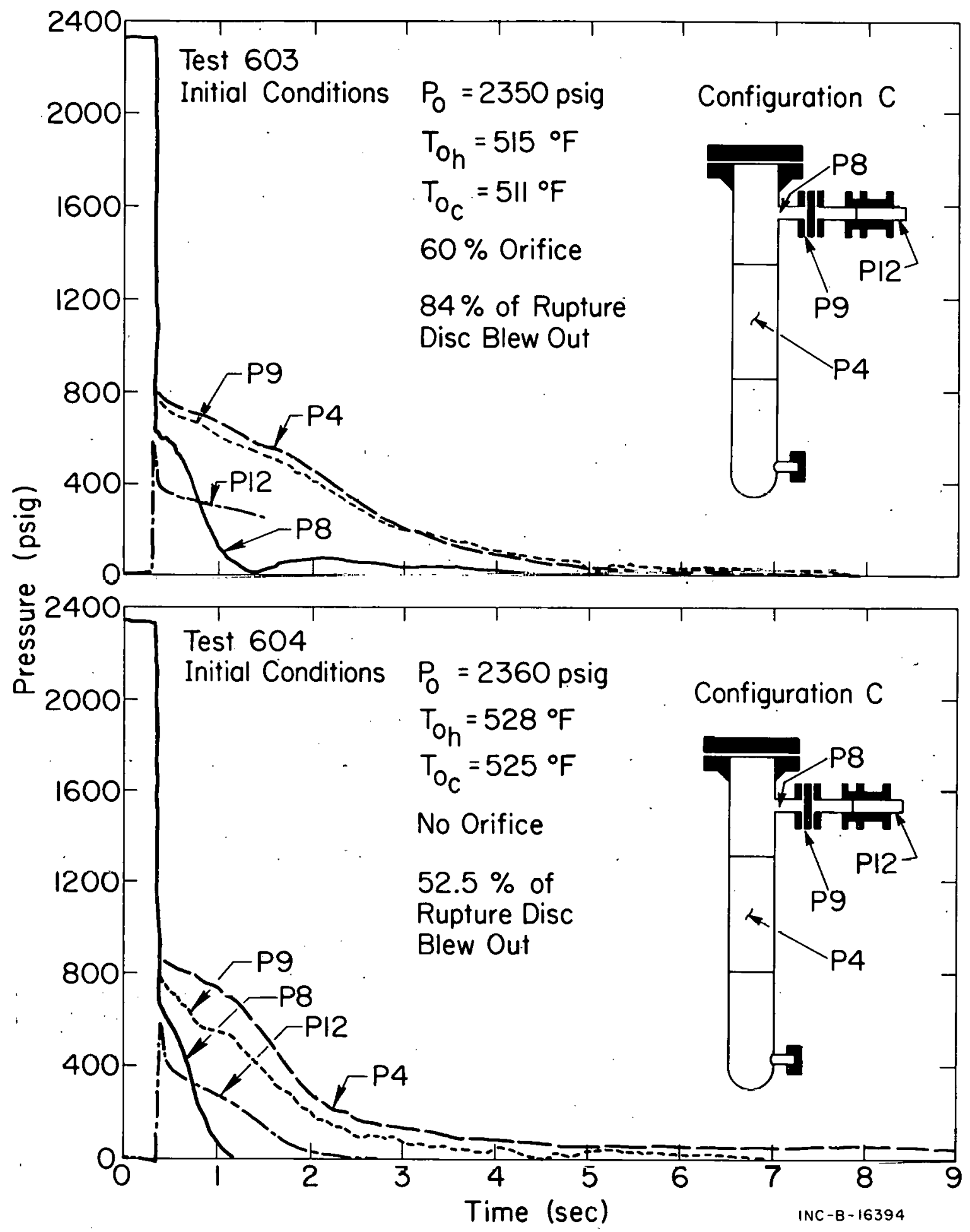

FIG. 27 PRESSURE BEHAVIOR IN EXIT PIPE FOR NORMAL AND ABNORMAL CONDITIONS OF CHOKING AT THE PIPE ENTRANCE. 
27. For this test, three identifiable regions of choking are observed; whereas, for most tests with no orifice, only two choking points were observed; one at the rupture disc and the other at the exit plane.

A rather marked difference is observed in the decompression history of the two tests of Figure 27 that cannot be readily accounted for since the initial conditions are essentially the same. This difference indicates that the nature and number of choking fronts within the exit pipe influence the mass efflux history.

Another index of the fluid behavior existing within, and dependent upon, the fluid envelope geometry, is the amount of water remaining in the vessel. The amount of water remaining is highly dependent upon such factors as vapor bubble concentration and coalescing, bubble rise velocities, L/D ratios of the vertical portions of the envelope, internal fluid restriction geometries, and system decompression rate. Figure 28 shows the amount of water remaining in

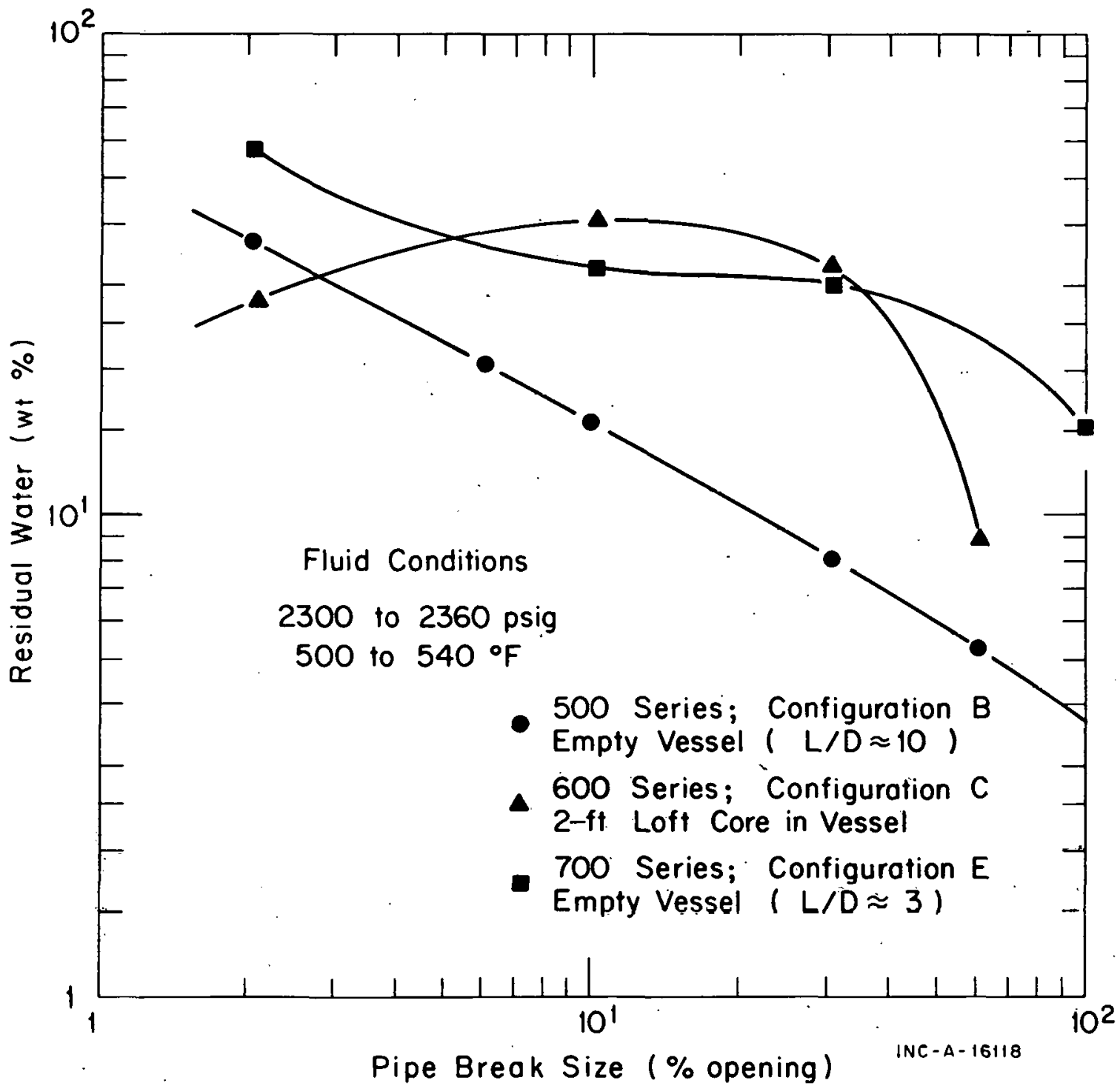

FIG. 28 RESIDUAL WATER IN VESSEL FOLLOWING DECOMPRESSION FOR.VARIOUS VESSEL GEOMETRIES AND BREAK CONDITIONS. 
several different envelope configurations for outlet breaks over a range of break sizes. The data for a vessel without internals (Configuration $B$ ) and an L/D of 10 clearly illustrate the high liquid carryover during phase separation for rapid decompression from large breaks in a long vessel.

The addition of simulated core restrictions (Configuration $C$ ) composed of unheated rods, to this vessel causes the vapor separation to be significantly increased except for very large and very small breaks. For the large breaks, the liquid-vapor mixture and carryover appear to be affected very little by the simulated core restrictions. For the smaller breaks, the decompression time becomes sufficiently long that the large ratio of simulated fuel rod surface area to fluid volume within the simulated core permits sufficient stored energy to be removed from the rods to cause boll-off of the liquid, which otherwise would have remained within the core volume. For the vessel with an L/D ratio of three (Configuration $E$ ) the phase separation process becomes extremely efficient, permitting nearly all the liquid which does not have sufficient enthalpy to flash to remain in the system.

\subsection{Structural Response to Coolant Decompression}

The structural response of the fluid envelope to the decompression process has been an important part of the experimental investigation for each phase of the program. The support structures for each of the fluid envelope configurations have been designed to be highly rigid in order to obtain a high natural frequency for the vessel and exit nozzle. A high natural frequency, or short natural period, is desirable for acquiring fast response measurements of the thrust loads generated in the early part of the blowdown, particularly for small-scale systems in which the decompression disturbances traverse the major dimensions of the system within a few milliseconds. Although the frequency response desired (approximately $800 \mathrm{~Hz}$ ) to acquire good thrust data for the subcooled regime was never achieved for the configurations presented, a frequency response of $300 \mathrm{~Hz}$ was obtained for Configurations $\mathrm{E}$ through $\mathrm{G}$. This response was adequate to study the total system thrust forces resulting during the two-phase portion of blowdown. Figure 29 depicts the thrust history for a top nozzle pipe break. The experimental thrust is compared to a calculated thrust that was obtained by using the expression:

$$
\mathrm{T}=\mathrm{PA}
$$

where:

$$
\begin{aligned}
& \mathrm{T}=\text { the thrist in the direction opposite to the fluid efflux } \\
& \mathrm{P}=\text { the gage pressure of the system } \\
& \mathrm{A}=\text { the area of the exit nozzle at the exit plane. }
\end{aligned}
$$

This thrust corresponds to integration of the sum of all the forces around the fluid envelope.

With the exception of the system "ringing" which is excited by the subcooled decompression, the calculated thrust compares favorably with the measured thrust and thus substantiates the technique for calculating thrust. 


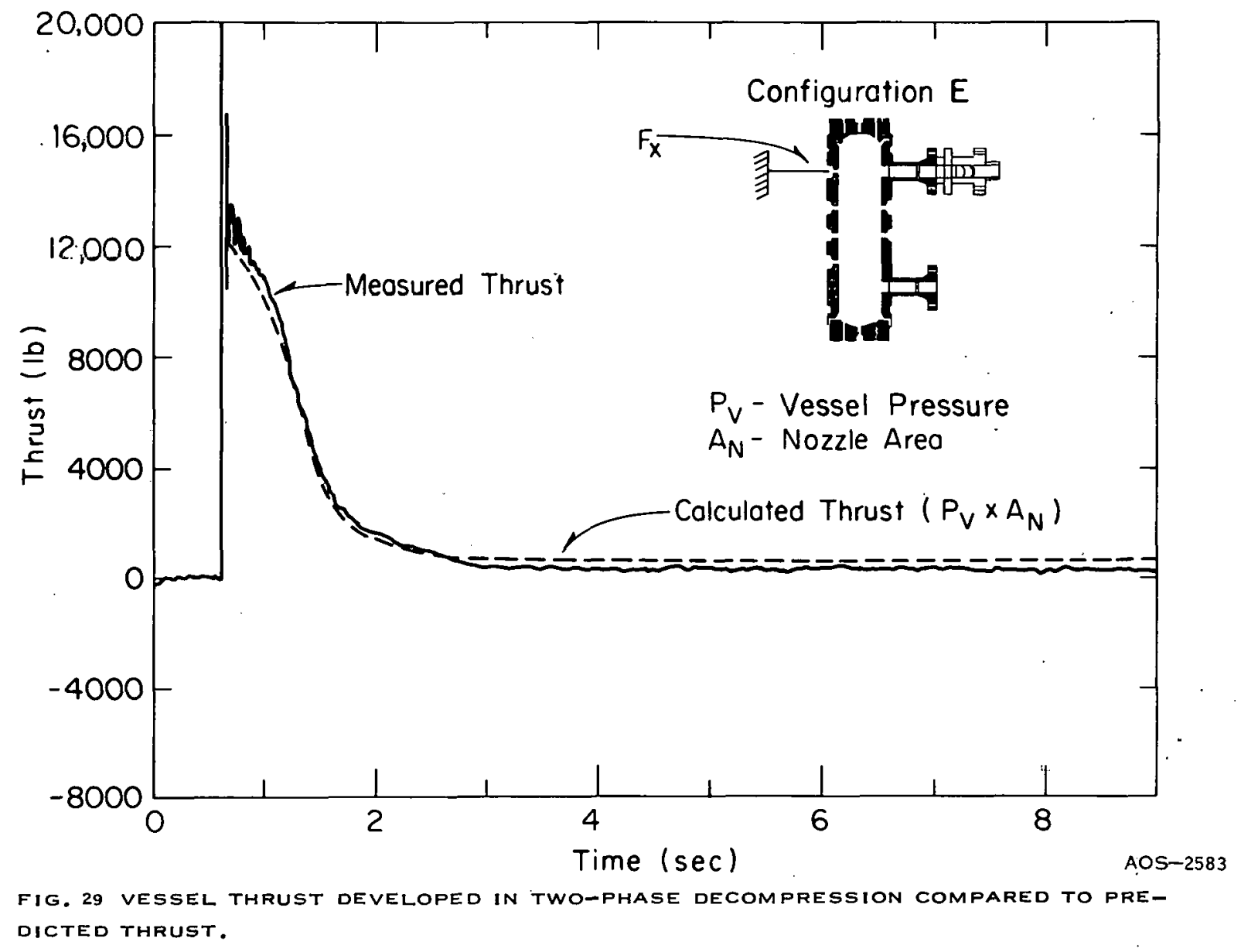

This technique indicates that for a fully open pipe break the thrust generated for this particular system is equal to PA not the theoretical maximum of 2 PA for incompressible fluid thrust. The difference between the actual and theoretical thrust can be attributed to momentum losses in the exit pipe.

Studies have also been conducted for a special pipe and plenum arrangement[15] to acquire data on subcooled thrust generation. The experiments have also shown the preceding thrust relationship to hold in the subcooled regime. The calculation becomes complex at any instant in time because the multiple reflected decompression disturbances represent a composite space gradient of pressure that requires that many nodes be used in the representation of the envelope surface in order to render the calculation accurate.

Also important to the structural response of a reactor system undergoing coolant decompression is the thermal stress generated in the envelope by the vigorous heat removal developed when the coolant temperature begins to drop to a value that will support nucleate boiling at the vessel and piping walls. Figure 30 is an example of the strain history results obtained at a point on the exit nozzle near the vessel for various system decompression rates. The strains presented are circumferential on the outer surface of the pipe and are compressive strains. The various strain histories, when compared to the approprlate decompression histories at the bottom of the figure, reveal that the maximum strain is developed near the end of the decompression 


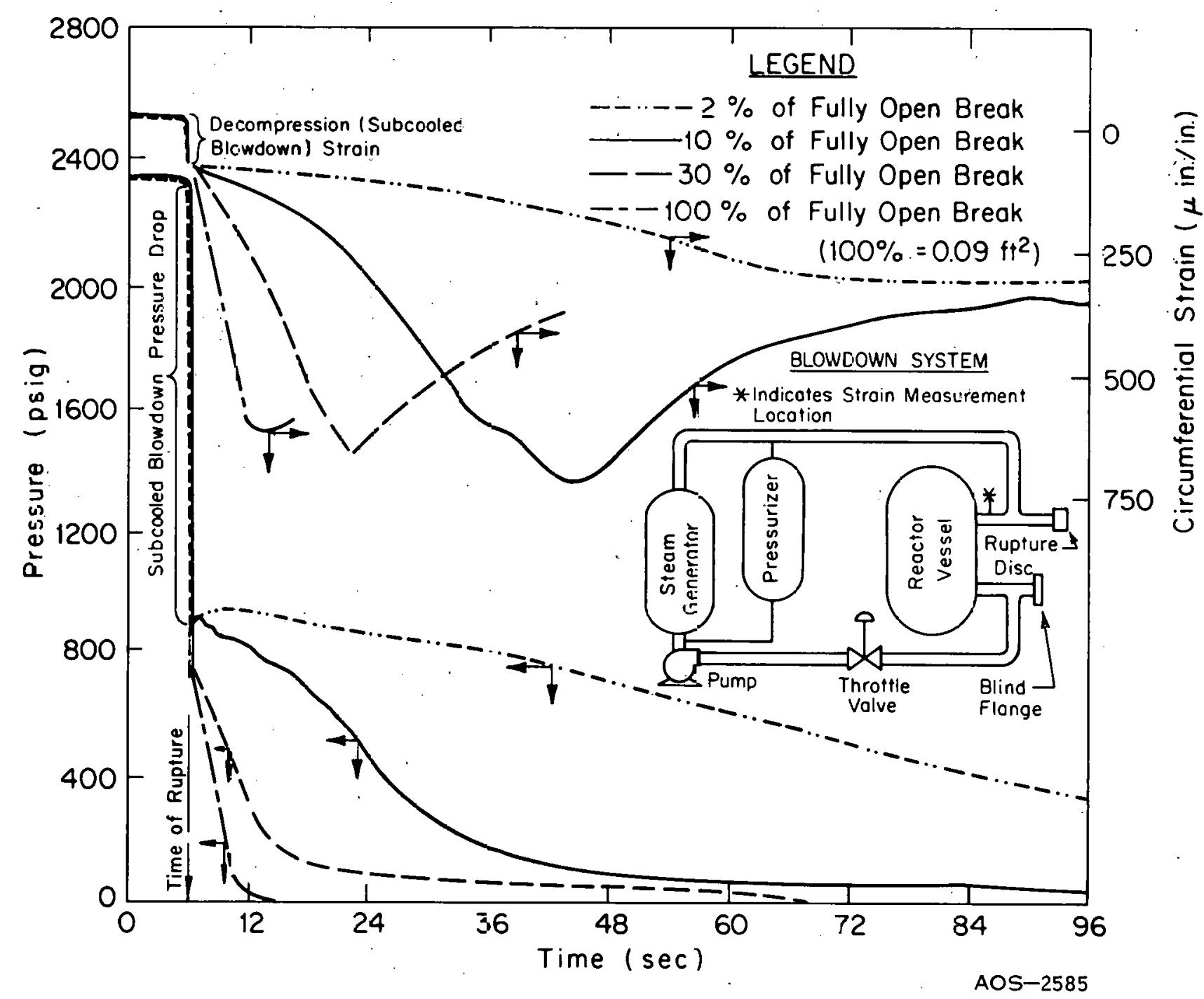

FIG. 30 THERMAL STRESS HISTORY DEVELOPED ON COOLANT PIPING DURING DECOMPRESSION FOR SEVERAL BREAK SIZES. 
history. At this time the bulk fluid temperature, corresponding to the appropriate pressure, differs from the average pipe wall temperature by as much as $200^{\circ} \mathrm{F}$ before film boiling occurs at the pipe wall. The maximum strain, as well as the maximum integrated energy removed from the pipe wall, is observed to be dependent on the decompression rate, or break size. For the $2 \%$ break the decompression rate is sufficiently slow that the heat within the pipe can be transported to the inner surface at a rate that prevents the development of differential thermal forces. For the very large breaks the decompression process is so rapid that very little heat is removed from the pipe before film boiling permits the temperature of the inner surface of the pipe to be restored to the bulk pipe temperature. The decompression rate resulting from a $10 \%$ pipe area break, however, is observed to generate the maximum strain and overall heat removal from the system. For this case the heat removal rate is comparable to the heat conduction rate within the pipe.

The axial and bending moment strains measured in the area of the top nozzle are about $80 \%$ of the circumferential strain. The strains measured at locations away from the top nozzle generally decrease in magnitude as the distance from the location of pipe rupture increases. For all tests, the measured strain is less than the yield strain which is approximately $800 \mu \mathrm{in} . /$ in. at test conditions. 


\section{DISCUSSION OF THE RELEVANCE OF THE \\ EXPERIMENTAL RESULTS}

Several important aspects of the foregoing presentation of results bear on the significance of decompression behavior to the reactor safety problem.

\section{SIGNIFICANCE OF BREAK RATE}

General agreement[18] exists that an instantaneous break will cause the subcooled decompression to be a problem from the standpoint of both hydraulic loads and core cooling capability. The question arises as to what is the minimum break opening time for which the system would not experience the adverse effects of the true instantaneous break. From the discussion of the first three figures in Section III (Figures 11, 12, and 13), the conclusion can be drawn that the first index of "how long is instantaneous" is simply the propagation velocity of a disturbance from one end of the structure of interest to the other end. For a 12-ft-long core, for example, a 3-msec break time would be indistinguishable from an instantaneous break in regard to loads. To significantly lessen the loads, the space gradient of the depressurization must be extended over a distance several times greater than the axial fluid path through a component such as the core or steam generator. The dominant influence on the space gradient of pressure in the reactor vessel is the upper or lower plenum depressurization rates. These rates are in turn controlled by the combination of the break rate, the ultimate break size, the distance from the break to the reactor vessel, and the effective ratio of the rupture pipe area to the connecting plenum area. For a break that is close to the reactor vessel and large in size, the break rate controls the plenum depressurization rate. However, if the break is 20 feet from the reactor vessel, for example, the roundtrip disturbance propagation time from the break opening to the vessel controls the plenum depressurization rate. The break opening time for this case would have to be excess of $15 \mathrm{msec}$ before the break rate would influence the blowdown behavior.

In summary, break times for large breaks in currently designed large power reactors (greater than $30 \%$ of the pipe area) over a wide range of distances from the break to the vessel area, must be in excess of 50 to $100 \mathrm{msec}$ before the subcooled decompression process can be ignored as a potential source of damage and of altering the fluid state in the core prior to the two-phase portion of blowdown.

\section{SIGNI FICANCE OF SUBCOOLED FLUID VELOCITY ON CORE}

\section{COOLING AND DRAG LOADS}

For large rapid breaks relatively close to the reactor vessel the fluid undergoes a sonic relaxation process that results in high fluid velocity in the exit pipe. The high fluid velocity and the location of the break, whether in the 
inlet or outlet piping, bear significantly on the state of the fluid within the primary system at the beginning of the two-phase portion of blowdown.

By way of example, for a hot-leg break and for a plenum-to-pipe diameter ratio of about ten, the fluid velocity in the plenum will be about one-tenth that in the pipe. The results of Figure 11 indicate that the plenum fluid velocity at the termination of the subcooled decompression would be about $30 \mathrm{ft} / \mathrm{sec}$ and must be algebraically added to the plenum fluid velocity existing prior to system rupture. In an operating power reactor in which the plenum cross-sectional area is three times that of the core and in which the initial plenum flow velocity is $15 \mathrm{ft} / \mathrm{sec}$, the core flow velocity is about $135 \mathrm{ft} / \mathrm{sec}$. The effect of this increased velocity for a hot-leg break is to incease the time before departure from nucleate boiling (DNB) is reached in the core. The increased timeto-DNB is desirable in that a great deal of the stored energy within the core is removed during this period. If the same break occurred in a cold leg, the subcooled fluid velocity change necessary to support the decompression process would result in the potential to bring the core fluid velocity to nearly zero, or in some cases to actually reverse the core flow existing prior to system rupture. Flow reversal in the core is undesirable because it may initiate early DNB and consequently demand early action of the emergency core cooling system while the blowdown process is still maintaining a high pressure.

One other important factor resulting from the high fluid velocity developed from large rapid breaks, is the drag loads placed upon structures in the flow field. Of principal concern is the drag loads on the control rod extension and guide tubes and the top grid holddown support stanchions.

\section{SIGNI FIC ANCE OF SUBCOOLED LOADS DURATION}

\section{TO DAMAGE PROCESS}

The pressure differentials observed in the earlier discussion of the semiscale results, Figures 17,18 , and 19, were relatively short in duration, and for the semiscale system, act as impulse loads, where impulse loads are defined as loads having durations shorter than the natural period of the st.mictures upon which they are applied. The factors controlling the scaling of these loads to the large machines must be considered. As discussed earlier, the experimental system from which the data have been acquired is roughly onetenth the linear scale of the $1000 \mathrm{MW}(\mathrm{e})$ system, and since the sonic transport times correspondingly differ by a factor of ten, the duration of the loads also differ by a factor of ten. However, the initial conditions of temperature and pressure are the same, making the magnitude of the depressurization events also the same. If, for example, the differential pressure loads observed in the previous figures were properly scaled to a large system, they would he about ten times the duration observed in the foregoing data, or about 20 to 30 msec.

To determine the significance of the longer duration, another important factor in the structural design of systems representing the internals of a reactor must be acknowledged. For many of the reactor systems that have been designed to datc, either small or large, the major members that support the 
core mass have natural periods of between 10 and $30 \mathrm{msec}$. The duration of the loads are thus seen to be comparable to the natural periods of the structures requiring then, that the structures withstand these loads according to steady state design criteria as opposed to impulse criteria for smaller systems.

\section{SIGNI FIC ANCE OF TWO-PHASE DECOMPRESSION BEHAVIOR}

Several important aspects of the experimental observations on two-phase decompression are significant to the development of two-phase decompression predictive techniques and the general reactor safety problem.

The general system pressure history of the decompression is a poor index of the fluid behavior taking place within the fluid envelope. To provide comprehensive evaluation of predictive analyses, particularly those that incorporate core heat transfer, future experiments must provide histories of local conditions of fluid state $(\rho, P, T)$ and fluid velocity. Where known pressure related phenomena such as choking are taking place, pressure measurements can provide an adequate index of characteristics of the two-phase process,

Considerably more experimental work is required in which representative reactor internal geometries are employed and across which a core differential temperature is initially established. This work is needed to ascertain for hot-leg breaks the core fluid behavior during the period in which the fluid quality and velocity of sound are low, causing the recovery of established flow within the core region to be delayed inordinately, thereby contributing to an early and rapid core heatup.

Experiments incorporating a complete primary loop must account, in the system configuration design, for most of the two-phase friction and area change pressure drops. Otherwise the system tested will neither develop the representative fluid flow from the stagnation point in the system nor produce the representative amount of water remaining following the blowdown.

The foregoing experimental requirements are being taken into account in the planning and execution of the remainder of the Semiscale Blowdown and Emergency Core Cooling (ECC) Project[1]. 


\section{REFERENCES}

1. H. W. Heiselmann and J. O. Zane, Semiscale Blowdown and Emergency Core Cooling. (ECC) Project, IN-1384 (July 1970).

2. H. D. Curet et al, Loss-of-Coolant Accident Analysis Program, IN-1382 (June 1970).

3. J. Dugone, D. E. Solberg, D. H. Walker, LOFT Integral Test Program, IDO-17258K (April 1969).

4. K. A.Dietz (ed:), Quarterly Technical Report, Engineering and Test Branch, October-December 1967, IDO-17242 (May 1968).

5. K. A. Dietz (ed.), Quarterly Technical Report, STEP Project, April-June 1967, IDO-17240 (September 1967).

6. K. A. Dietz (ed.), Quarterly Technical Report, STEP Project, JanuaryMarch 1967, IDO-17239 (August 1967).

7. K. A. Dietz (ed.), Quarterly Technical Report, STEP Project, OctoberDecember 1966, IDO-17214 (April 1967).

8. K. A. Dietz (ed.), Quarterly Technical Report, STEP Project, July-September 1966, IDO-17213 (April 1967).

9. K. A. Dietz (ed.) Quarterly Technical Report, STEP Project, April-June 1966, IDO-17187 (January 1967).

10. K. A. Dietz (ed.), Quarterly Technical Report, STEP Project, JanuaryMarch 1966, IDO-17186 (November 1966).

11. K. A. Dietz (ed.), Quarterly Technical Report, STEP Project, OctoberDecember 1965, IDO-17167 (September 1966).

12. K. A. Dietz (ed.), Quarterly Technical Report, LOFT Program Office, April-June, 1969, IDO-17303 (March 1970).

13. L. E. Kinsler and A. R. Frey, Fundamentals of Acoustics, 2nd ed., New York: John Wiley and Sons, Inc., (1962).

14. V. T. Berta, Subcooled Pressure Gradient Calculations in PWR Systems Following Primary Coolant Loop Breaks, IDO-17243 (Marrh 1968).

15. G. H. Hanson, Subcooled-Blowdown Forces on Reactor System Components: Calculational Method and Experimental Confirmation, IN-1354 (June 1970).

16. A. R. Edwards, Conduction Controlled Flashing of a Fluid, and the Prediction of Critical Flow Rates in a One-Dimensional System, AHSB(S) R-147 (1968). 
17. R. P. Rose, Steam Jet Pump Analysis and Experiments, Bettis Atomic Power Laboratory, WAPD-TM-227 (June 1960).

18. Emergency Core Cooling. Report of Advisory Task Force on Power Reactor Emergency Cooling, AEC, Washington, D. C., TID-24226 (1967). 